\title{
Magnetohydrodynamic Nanoliquid Thin Film Sprayed on a Stretching Cylinder with Heat Transfer
}

\author{
Noor Saeed Khan ${ }^{1}$, Taza Gul ${ }^{1, *}$, Saeed Islam ${ }^{1}$, Ilyas Khan ${ }^{2}$, Aisha M. Alqahtani ${ }^{3}$ \\ and Ali Saleh Alshomrani ${ }^{4}$ \\ 1 Department of Mathematics, Abdul Wali Khan University, Mardan 32300, Khyber Pakhtunkhwa, Pakistan; \\ noorsaeedkhankhattak@gmail.com (N.S.K.); saeedislam@awkum.edu.pk (S.I.) \\ 2 Basic Engineering Sciences Department, College of Engineering, Majmaah University, \\ Majmaah 11952, Saudi Arabia; ilyaskhanqau@yahoo.com \\ 3 Department of Mathematics, Princess Nourah bint Abdulrahman University, Riyadh 11564, Saudi Arabia; \\ Alqahtani@pnu.edu.sa \\ 4 Department of Mathematics, Faculty of Science, King Abdulaziz University, Jeddah, 21577, Saudi Arabia; \\ aszalshomrani@kau.edu.sa \\ * Correspondence: tazagulsafi@yahoo.com; Tel.: +92-331-911-7160
}

Academic Editor: Rahmat Ellahi

Received: 31 January 2017; Accepted: 3 March 2017; Published: 10 March 2017

\begin{abstract}
The magnetohydrodynamic thin film nanofluid sprayed on a stretching cylinder with heat transfer is explored. The spray rate is a function of film size. Constant reference temperature is used for the motion past an expanding cylinder. The sundry behavior of the magnetic nano liquid thin film is carefully noticed which results in to bring changes in the flow pattern and heat transfer. Water-based nanofluids like $\mathrm{Al}_{2} \mathrm{O}_{3}-\mathrm{H}_{2} \mathrm{O}$ and $\mathrm{CuO}-\mathrm{H}_{2} \mathrm{O}$ are investigated under the consideration of thin film. The basic constitutive equations for the motion and transfer of heat of the nanofluid with the boundary conditions have been converted to nonlinear coupled differential equations with physical conditions by employing appropriate similarity transformations. The modeled equations have been computed by using HAM (Homotopy Analysis Method) and lead to detailed expressions for the velocity profile and temperature distribution. The pressure distribution and spray rate are also calculated. The comparison of HAM solution predicts the close agreement with the numerical method solution. The residual errors show the authentication of the present work. The $\mathrm{CuO}-\mathrm{H}_{2} \mathrm{O}$ nanofluid results from this study are compared with the experimental results reported in the literature showing high accuracy especially, in investigating skin friction coefficient and Nusselt number. The present work discusses the salient features of all the indispensable parameters of spray rate, velocity profile, temperature and pressure distributions which have been displayed graphically and illustrated.
\end{abstract}

Keywords: magnetohydrodynamic; nanoliquid thin film; $\mathrm{Al}_{2} \mathrm{O}_{3}-\mathrm{H}_{2} \mathrm{O} ; \mathrm{CuO}-\mathrm{H}_{2} \mathrm{O}$; spray; heat transfer; stretching cylinder; homotopy analysis method; numerical method; residual errors; skin friction coefficient; nusselt number

\section{Introduction}

Recently heat transfer technology is related with the cooling applications of miniaturized high heat flux components. The fluids traditionally used for heat transfer applications such as water, oils and ethylene glycol have comparatively low thermal conductivity and do not meet the required demand as an efficient heat transfer agent. The conventional technique for increasing heat dissipation is to increase the area available for exchanging heat with a heat transfer fluids, but this process needs an undesirable increase in the size of thermal management system. So by taking into account the rising demands of modern technology, comprising chemical production, power stations and 
microelectronics, there is a need to propose new types of fluids which are more effective with respect to heat exchange performance. For this purpose nanofluids are constructed to ensure effective thermal conductivity enhancements and to fulfill the rising demands of cooling/heating and other needs. Nanofluid is a dispersion consisting of nanometer-sized particles, called naoparticles. Nanoliquids are dispersions formulated as a violent encounter of moving nanoparticles in a base liquid. These particles utilized in nanofuids are generally constructed from metallic elements $(\mathrm{Al}, \mathrm{Cu})$, oxides $\left(\mathrm{Al}_{2} \mathrm{O}_{3}\right)$, nitrides (AlN, SiN) or nonmetallic elements (graphite, carbon nanotubes) and a liquid of conduction nature like water or ethylene glycol usually used as the base fluid. Oily products, biofluids and polymer suspensions may are used as base fluid. Nanoparticles have the diameters in the range 1 and $100 \mathrm{~nm}$. For ensuring improved transfer of heat enhancements, nanofluids generally include up to $5 \%$ volume fraction of nanoparticles. Due to strange characteristics of nanoliquids that make them capable in many applications in hybrid-powered engines, pharmaceutical processes, fuel cells, including microelectronics and heat transfer. It has been widely used in engineering devices for ship-sand in boiler flue gas reduction of temperature and defense, in space, in machining, in grinding, nuclear reactor and heat exchanger, chiller, domestic refrigerator and engine vehicle thermal/cooling management. Nanofluids makes better the thermal conduction of the base liquid extremely, therefore in the analysis of flow of nanofluids the researchers are deeply interested. Nanofluids are also very consistent and have no supplementary issues like additional pressure drop, erosion and sedimentation. For the first time Choi [1] introduced the nanofluid technology. Utilizations in the superconducting magnets and super fast computing are facing problems in thermal management. Thermal properties of nanofluids are extensive research area during the past few decades for their perspective technological applications in electronics cooling and heat transfer. Yu et al. [2] analyzed the thermal transport properties of ethylene glycol-based nanofluids experimentally by measuring the thermal conductivity and viscosity. In another study $\mathrm{Yu}$ et al. [3] investigated experimentally the rheological effects and heat transfer properties of $\mathrm{Al}_{2} \mathrm{O}_{3}$ nanofluids based on the mixtures $45 \mathrm{vol}$. \% ethylene glycol and 55 vol. \% water. With the discovery of carbon nanotubes (CNTs) in 1991, carbon-based nanomaterials are popular for their unique physical, thermal, mechanical and electrical properties. Chen et al. [4] employed a green method to make composites of multi-walled carbon nanotubes (MWNTs) decorated with silver nanoparticles (Ag-NPs). In case of graphene, a single atomic layer of graphite, which is a two dimensional form of carbon, is found to show good crystal quality and to have ballistic electronic transport at room temperature. It has been evolving as a fascinating material having unique physical, chemical and mechanical properties as investigated by Xie and Chen [5]. Nanofluids containing graphene oxide nanosheets have substantially higher thermal conductivities than the base fluid as analyzed by Yu et al. [6]. It is very necessary to know more about heat transfer properties of fluids due to the different speculated applications. It is a fact that the study of heat transfer techniques can enhance the comprehensive understanding of physical phenomena like convection and boiling. The effective thermal conductivity is one of the most controversial topics in nanofluids. In addition, the physical nature is still far from being well understood due to its complexity and diversity. After detailed analysis, Brownian motion induced convection and effective conduction through percolating nanoparticle paths are taken to be the two most probable mechanisms that yield the improved heat conduction in nanofluids. Through a mechanistic point of view, although the effects of some parameters such as the average size of nanoparticles and nanoparticles concentration have been discussed in literatures [1-4], yet an overall mechanistic description is not available. It is a problem to investigate the effective thermal conductivity of nanofluids analytically due to the extremely complicated mechanisms of heat transfer and the interrelationship between thermal conductivity and the size of nanoparticles and the nanoparticles concentration. Therefore the clear mechanism of heat transfer is still not known in nanofluids. To fill this gap Xiao et al. [7] attempted to derive the analytical expressions for effective thermal conductivity of nanofluids while taking into account the effect of heat convection due to the Brownian motion of nanoparticles based on the fractal theory. Similarly Cai et al. [8] investigated the advances of nanoparticles researches by introducing the fractal theory presenting the fractal model of 
thermal conductivity of nanofluids under the consideration of fractal distribution of nanoparticles sizes and heat convection between nanoparticles and liquids due to the Brownian motion of nanoparticles in fluids, in which the nanoparticles are assumed to be dispersed. Buongiorno [9] considered a detailed discussion about the nanofluid. Ellahi [10] explored the effects of MHD and temperature dependent viscosity on the flow of a non-Newtonian nanofluid in a pipe. Khan and Pop [11] elaborated the motion of a nanofluid passing a stretching surface. The effects of wall behavior for the peristaltic flow of a nanofluid were described by Mustafa et al. [12]. Akbar and Nadeem [13] investigated the endoscopic exploration of peristaltic flow of a nanofluid. Nowar [14] solved the problem of peristaltic flow of a nanofluid in the regime of Hall current and porous medium. A vast study exploring different aspects of nanofluid may be consulted in the references [15-23].

A magnetic nanofluid is a special substance having the combined features of fluid and magnetic characteristics. These fluids are practiced resulting in numerous distinguished utilizations like magneto-opticle wavelength filters, and other substances related to optic like nonlinear materials and tunable fiber filters, gratings and switches. Several types of physical characteristics of such fluids are changed by the help of varying the intensity of magnetic field. Nanofluids related to magnetism assume presently a broad application in several departments such as biomedicine, medicine and in sink float isolation. Too many biomedical uses that contains nanofluids, like drug supply, magnetic cell separation and negative growth in magnetic resonance imaging are most important. Magnetohydrodynamic (MHD) motions are significant due to their use in power generators, MHD accelerators, refrigerations coils, transmissions lines, electric transformers and heating elements. Due to the scope of this notion, several researchers have done their work on magnetohydrodynamic motions. It is a proved statement that energy transfer is possible due to composition (concentration) gradient and mass transportation is occurred due to temperature gradient. These contributions of MHD motion are utilized in levitation and pumping of fluids in mechanical engineering, controlling of liquid motion and transpiration procedures and aerodynamics. In extrusion process, investigation of transfer of heat in boundary layer flow past the stretching surfaces has wide uses. The cooling technique has to be controlled completely because the standard of final product relies the rate of transfer of heat. The desired quality of manufactured product may be achieved by the magnetohydrodynamic motion in electrically conducting liquid which can control the influence of cooling. Important industrial applications of the problem of viscous motion and transfer of heat past a stretching sheet are, for example, in few technical procedures like glass fiber production, manufacturing of foods and paper, continuous casting, wire drawing, in metallurgical techniques, such as crystal making, preparing of plastic and rubber sheets, enameling and painting of bronze threads and many others. The issues in molten form after some time stretched from a slit to obtain the required size during the manufacturing of these sheets. Due to the cooling stretching rate in the process and the process of stretching the final product with the required properties is prepared. Chamkha et al. [24] analyzed the Brownian motion and thermophoretic influences on the mixed convection MHD motion of a nanoliquid past a stretching porous medium. During suction/injection the discussion of time dependent magnetohydrodynamic motion of a nanoliquid past a vertical stretching surface is carried out by Kandasmy et al. [25]. Enough research work on motion past stretching surfaces has been carried out. Sakiadis [26] was the first one who considered the flow on continuous flat and solid surfaces. Crane [27] investigated the flow past an extensible surface by assuming the surface velocity varying in a linear way with an extent of space from the slit. Vajravelu et al. [28] determined the solution of the problem of magnetohydrodynamic motion of a non-Newtonian liquid past a stretching surface. Abu-Nada [29] examined the impacts of variable properties of $\mathrm{Al}_{2} \mathrm{O}_{3}$ water nanoliquid on the improvement of transfer of heat in natural convection. Nasrin and Alim [30] investigated the heat generation by nanofluid of variable properties with flat plate solar collector.

Thin film fluid flows are the subject of considerable attention in research. Khan et al. [31] reported the influences of variable properties of a thin liquid film motion past a contracting/expanding space. Recently, The behavior of flow and transfer of heat of a second-grade fluid through a porous medium 
past a stretching sheet is discussed by Khan et al. [32]. In another study, Khan et al. [33] investigated thermophoresis and thermal radiation with heat and mass transfer in a magnetohydrodynamic thin film second grade fluid of variable properties past a stretching sheet. Aziz et al. [34] reported thin film motion and transfer of heat on a time dependent stretching sheet with internal heating. The thin film Williamson nanofluid flow with varying viscosity and thermal conductivity on a time dependent sheet was analyzed by Khan et al. [35]. Qasim et al. [36] discussed transfer of heat and mass in a nanofluid past a time dependent stretching surface using Buongiorno's model. Prashant et al. [37] presented transfer of heat on a time dependent stretching surface with thermal radiation, internal heating in case of external magnetic field for a thin film flow. Kumari et al. [38] investigated transfer of heat and mass in a nanofluid past an unsteady stretching surface.

During past several years, a prominent revolution has been occurred in the analysis of motion and transfer of heat past slender cylinders. The inevitable needs of the utilization of slender objects which minimizes the drag and producing complete lift to support the body in some situations. In case of slender cylinder, the radius is possible to have same as the boundary layer thickness and the motion is taken as axisymmetric instead of two dimensional and the transverse curvature term existing in the governing equation which by force affects the velocity and temperature fields. Related to this notion, the coefficient of skin friction and rate of transfer of heat at the wall are affected too by the normal curvature. Motion past a cylinder and the corresponding transfer of heat characteristics have extensive applications like preparing of heat exchanger tubes, chimney stacks, cooling towers, offshore structure, thin film condensation and paper production. It is also utilized in petroleum industries, plasma studies and geothermal energy extractions. Wang [39] was the the first to analyze the flow in viscous case past a stretching hollow cylinder by evaluating the third order non-linear complicated system. The motion of a fluid outside a stretching cylinder by using Keller-box technique for the solution is elaborated by Ishak et al. [40]. Wang [41] obtained the similarity solution of a natural convective study over a non-horizontal stretching cylinder. The numerically solution of the problem of MHD motion and transfer of heat of Newtonian liquid past a stretching cylinder is obtained by Elbashbeshy [42]. Ashorynejad et al. [43] reported the motion of a nanofluid with transfer of heat and magnetic field past a stretching cylinder. Rangi and Ahmad [44] analyzed the motion and transportation of heat of a Newtonian incompressible liquid past a stretching cylinder with variable fluid property. Sheikholeslami [45] discussed the effect of uniform suction of a nanofliquid motion and transfer of heat past a stretching cylinder. Wang [46] explored the liquid film sprayed on a stretching cylinder. Koo and Kleinstreuer [47] described the viscous dissipation effects in micro channels. Koo [48] investigated the computational fluid flow with transfer of heat used in micro systems. Other investigations about nanofluids and different interesting problems with respect to different aspects are exist in the references [49-54].

The literature survey shows that there is a large amount of investigations about the nanofluids. Still there is no exploration to discuss the magnetohydrodynamic thin liquid film sprayed on a stretching cylinder with transfer of heat features of $\mathrm{CuO}-\mathrm{H}_{2} \mathrm{O}$ nanofluid. To fill this gape in this regard, claim is exist for the first try to analyze the sprayed liquid thin film effect on magnetohydrodynamic two dimensional $\mathrm{CuO}-\mathrm{H}_{2} \mathrm{O}$ nanofluid past a stretching cylinder with heat transfer. Employing appropriate transformations the basic constitutive systems of equations of the problem are converted to dimensionless form. The problem has been solved by using a powerful analytic tool HAM (Homotopy Analysis Method) [55-58]. The influences of all the emerging parameters on spray rate, velocity profile as well as temperature and pressure distributions have been demonstrated in figures.

\section{Materials and Methods}

\section{Basic Equations}

A motion of a steady and axi-symmetric sprayed liquid thin film $\mathrm{CuO}-\mathrm{H}_{2} \mathrm{O}$ nanofluid past a stretching cylinder in two dimensions is considered in the presence of magnetic field. The magnetic 
field is uniform of intensity $B_{0}$ acting in the radial way. The Reynolds number due to magnetic field $\left(R e_{m}=\sigma_{n f} \mu_{e} W_{w} \delta\right.$, where $\sigma_{n f}, \mu_{e}, W_{w}$ and $\delta$ stand for the electrical conductivity of the nanofluid, magnetic permeability, surface velocity and thickness of the fluid film respectively) is taken less in magnitude as compared to the applied magnetic field. Ignoring viscous dissipation by taking it very less in amount. When the material stretches, the thickness of the cylinder reduces but the outer radius $a$ of the cylinder remains fixed. An axisymmetric spray in a radial direction having velocity $V$ condenses as a film and is dragged along through the help of outer surface of the cylinder. Also, it is suppose that the base fluid and the nanoparticles are in thermal equilibrium prevailing the absence of slip. Selecting $z$-axis along the cylinder and $r$-axis is taken radially, as depicted in Figure 1.

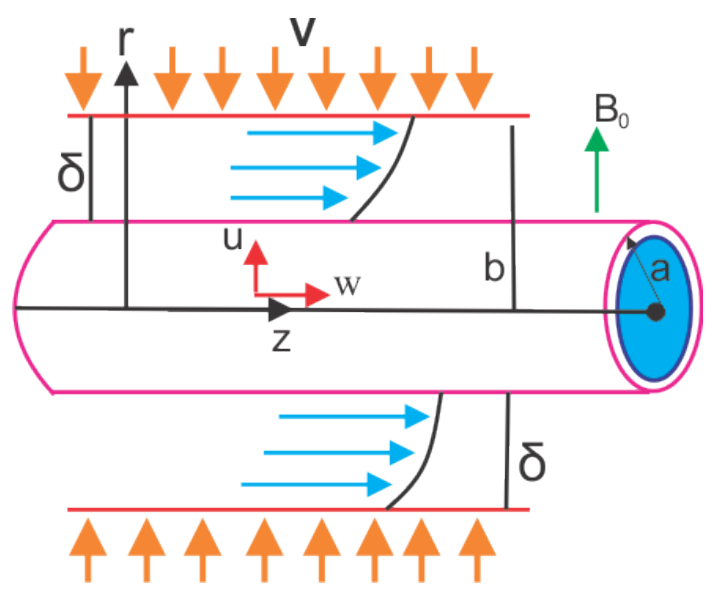

Figure 1. Geometry of the Physical Model.

According to the above statement, in cylindrical coordinates $(r, z)$, the equations of continuity, momentum and energy, governing the film in scalar form are:

$$
\begin{gathered}
\frac{\partial(r u)}{\partial r}+\frac{\partial(r w)}{\partial z}=0 \\
\rho_{n f}\left(u \frac{\partial u}{\partial r}+w \frac{\partial u}{\partial z}\right)=-\frac{\partial P}{\partial r}+\mu_{n f}\left(\frac{1}{r} \frac{\partial u}{\partial r}-\frac{u}{r^{2}}+\frac{\partial^{2} u}{\partial r^{2}}\right), \\
\rho_{n f}\left(u \frac{\partial w}{\partial r}+w \frac{\partial w}{\partial z}\right)=\mu_{n f}\left(\frac{1}{r} \frac{\partial w}{\partial r}+\frac{\partial^{2} w}{\partial r^{2}}\right)-\sigma_{n f} B_{0}^{2} w \\
\rho_{n f}\left(u \frac{\partial T}{\partial r}+w \frac{\partial T}{\partial z}\right)=\frac{k_{n f}}{\left(\rho C_{P}\right)_{n f}}\left(\frac{1}{r} \frac{\partial T}{\partial r}+\frac{\partial^{2} T}{\partial r^{2}}\right),
\end{gathered}
$$

where the components of velocity are $u(r, z)$ and $w(r, z)$, the magnetic induction is $B=\left(B_{0}, 0,0\right)$, $P$ expresses the pressure and $T$ is the fluid temperature. Further, $\rho_{n f}, \mu_{n f},\left(C_{P}\right)_{n f}$ and $k_{n f}$ are the density, viscosity, heat capacitance and thermal conductivity of the nanofluid respectively. The subscript " $n f$ " is used for the nanofluid. The effective density $\left(\rho_{n f}\right)$ and the heat capacitance $\left(\rho C_{P}\right)_{n f}$ which are the relation between base fluid and nanoparticles are defined as

$$
\begin{gathered}
\rho_{n f}=\rho_{f}(1-\phi)+\rho_{s} \phi_{s}, \\
\left(\rho C_{P}\right)_{n f}=\left(\rho C_{P}\right)_{f}(1-\phi)+\left(\rho C_{P}\right)_{s} \phi,
\end{gathered}
$$

where $\phi$ describes the solid volume fraction and the subscript " $s$ " is used for nanosolid particles. The boundary conditions are

$$
u=U_{w}, \quad w=W_{w}, \quad T=T_{w}, \quad \text { at } \quad r=a,
$$




$$
\frac{\partial w}{\partial r}=\frac{\partial \delta}{\partial r}=\frac{\partial T}{\partial r}=0, \quad u=\frac{d \delta}{d z} \quad \text { at } \quad r=b,
$$

where $U_{w}=-c a, W_{w}=2 c z, T_{w}(z)=T_{b}-T_{r e f}\left[\frac{c z^{2}}{v_{n f}}\right]$.

The subscript " $w$ " is used for condition at the surface, $c>0$ is the stretching rate, $a$ is the outer radius of the cylinder and $b$ is the outer radius of the film. $v_{n f}=\frac{\mu_{n f}}{\rho_{n f}}$ is the kinematic viscosity of the nanofluid, $T_{b}$ is the temperature at the outer radius of the film surface and $T_{r e f}$ is the reference temperature such that $0 \leq T_{r e f} \leq T_{b}$. The argument $\frac{c z^{2}}{v_{n f}}$ in $T_{r e f}\left[\frac{c z^{2}}{v_{n f}}\right]$ shows the stretching velocity along $z$-axis [31-38].

Introducing the transformations for nondimensional variables $f, \theta$ and similarity variable $\zeta$ as

$$
u=-c a \frac{f(\zeta)}{\sqrt{\zeta}}, \quad w=2 c z f^{\prime}(\zeta), \quad T(z)=T_{b}-T_{r e f}\left[\frac{c z^{2}}{v_{n f}}\right] \theta(\zeta), \quad \zeta=\left(\frac{r}{a}\right)^{2} .
$$

For the outer radius $b$ of the film,

$$
\zeta=\left(\frac{b}{a}\right)^{2}=\beta_{1}
$$

where $\beta_{1}$ is the nondimensional film thickness parameter. Equation (9) automatically satisfies mass conservation Equation (1). Utilizing Equations (9)-(10) in Equations (3), (4), (7) and (8) yield the following four Equations (11)-(14)

$$
\begin{gathered}
\zeta f^{\prime \prime \prime}+f^{\prime \prime}-\operatorname{Re} B_{1}(1-\phi)^{2.5}\left(f^{2}-f f^{\prime \prime}\right)-M f^{\prime}=0, \\
\zeta \theta^{\prime \prime}+\theta^{\prime}-\operatorname{RePr}\left(\frac{B_{2}}{B_{3}}\right)\left(2 f^{\prime} \theta-f \theta^{\prime}\right)=0, \\
f=f^{\prime}=\theta=1 \text { at } \zeta=1, \\
f^{\prime \prime}=\theta^{\prime}=0 \quad \text { at } \zeta=\beta_{1},
\end{gathered}
$$

where prime (') is the derivative with respect to $\zeta . \operatorname{Re}=\frac{c a^{2}}{2 v_{n f}}, \operatorname{Pr}=\frac{\mu_{n f}\left(\rho C_{P}\right)_{f}}{\rho_{f} K_{f}}$ and $M=\frac{a^{2} B_{0}^{2} \sigma_{n f}}{4 \mu_{n f}}$ are respectively the stretching Reynolds number, Prandtl number and magnetic field parameter. The parameters $B_{1}, B_{2}, B_{3}$ are defined as

$$
\begin{gathered}
B_{1}=\frac{\rho_{s}}{\rho_{f}} \phi(1-\phi), \\
B_{2}=\frac{\left(\rho C_{P}\right)_{s}}{\left(\rho C_{P}\right)_{f}} \phi(1-\phi), \\
B_{3}=\frac{k_{n f}}{k_{f}}=\frac{2 k_{f}+k_{s}-2\left(k_{f}-k_{s}\right) \phi}{2 k_{f}+k_{s}+\left(k_{f}-k_{s}\right) \phi},
\end{gathered}
$$

$k_{f}$ and $k_{s}$ denote the thermal conductivity of the base fluid and nanosolid particles respectively. A subscript " $f$ " is used for base fluid.

Evaluating Equation (2) for the pressure $P$

$$
\frac{P}{\rho_{n f}}=\frac{P_{\infty}}{\rho_{n f}}-\frac{(c a)^{2} f^{2}}{2 \zeta}-2 c v_{n f} f^{\prime}
$$

$$
\frac{P-P_{\infty}}{c \mu_{n f}}=-\frac{\operatorname{Re} B_{1}(1-\phi)^{2.5} f^{2}}{\zeta}-2 f^{\prime}
$$


The shear stress on the outer film surface is zero, i.e.,

$$
f^{\prime \prime}\left(\beta_{1}\right)=0 .
$$

On the cylinder the shear stress is

$$
\tau=\frac{\rho_{n f} v_{n f} 4 c z f^{\prime \prime}(1)}{a}=\frac{4 c \mu_{n f} z f^{\prime \prime}(1)}{a} .
$$

Estimation of skin friction coefficient $\left(C_{f}\right)$ and heat transfer coefficient $(N u)$ which are very important through the industrial application point of view are also calculated in this study. The equation defining the skin friction $\left(C_{f}\right)$ is

$$
C_{f}=\frac{2 \tau_{w}}{\rho w_{w}^{2}},
$$

where

$$
\tau_{w}=\mu_{n f}\left(\frac{\partial w}{\partial r}\right)_{r=a},
$$

i.e.,

$$
\tau_{w}=\frac{\rho_{n f} v_{n f} 4 c z f^{\prime \prime}(1)}{a}=\frac{4 c \mu_{n f} z f^{\prime \prime}(1)}{a} .
$$

Using Equation (22), one obtains:

$$
C_{f}=\left|\frac{1}{A_{1}(1-\phi)^{2.5}} f^{\prime \prime}(1)\right|,
$$

The equation defining the Nusselt number $(\mathrm{Nu})$ is:

$$
N u=\frac{a q_{w}}{k\left(T_{w}-T_{b}\right)},
$$

where $q_{w}$ is the surface heat flux and is given by

$$
\begin{gathered}
q_{w}=-k_{n f}\left(\frac{\partial T}{\partial r}\right)_{r=a} . \\
q_{w}=-2 k_{n f} \frac{\left(T_{w}-T_{b}\right)}{a} \theta^{\prime}(1) .
\end{gathered}
$$

Using Equation (26), one obtains

$$
N u=-2 \frac{k_{n f}}{k_{f}} \theta^{\prime}(1) .
$$

The deposition velocity $V$ in terms of film thickness $\beta_{1}$ is given by

$$
-c a \frac{f\left(\beta_{1}\right)}{\sqrt{\beta_{1}}}=-V .
$$

Mass flux $m_{1}$ is another interesting quantity which is in connection with the deposition per axial length is

$$
m_{1}=V 2 \pi b
$$

The normalized mass flux $m_{2}$ is

$$
m_{2}=\frac{m_{1}}{2 \pi a^{2} c}=\frac{m_{1}}{4 \pi v R e}=f\left(\beta_{1}\right)
$$


The Brownian motion bears a leading role in the effective thermal conductivity. The effective thermal conductivity is made of particle's conventional static and a Brownian motion part and describes the influences of size, volume fraction, temperature dependence, the type of particle and the base fluid combinations [47].

$$
\begin{gathered}
k_{\text {eff }}=k_{\text {static }}+k_{\text {Brownian }} \\
\frac{k_{\text {static }}}{k_{f}}=1+\frac{3\left(\frac{k_{p}}{k_{f}}-1\right) \phi}{\left(\frac{k_{p}}{k_{f}}+2\right)-\left(\frac{k_{p}}{k_{f}}-1\right) \phi},
\end{gathered}
$$

where $k_{\text {static }}$ denotes the static thermal conductivity which depends on the Maxwell classical correlation. The enhanced thermal conductivity component generated due to micro-scale convective transfer of heat of a particles's Brownian motion and influenced by ambient fluid flow is obtained through simulating Stoke's motion with a nanoparticle. Utilization of empirical functions ( $\beta$ and $f$ ) [48] combines the interaction among nanoprticales with the temperature influence in the model, giving to

$$
k_{\text {Brownian }}=5 \times 10^{4} \beta \phi \rho_{f} C_{p, f} \sqrt{\frac{K_{b} T}{\rho_{p} d_{p}}} f(T, \phi) .
$$

The thermal interfacial resistance (Kapitza resistance) $[49,50]$ exists with the adjacent layers of the both types of materials; the thin barrier layer has a prominent activity in weakening the effective thermal conductivity of the nanoparticle. Li [51] revisited the work of Koo and Kleinstreuer [52] composing a new $g^{\prime}$-function by using $\beta$ and $f$ functions having the effects of particle diameter, temperature and volume fraction. The empirical $g^{\prime}$-function is reliant to the used nanofluid [52]. Also, by proposing $R_{f}=4 \times 10^{-8} \mathrm{~km}^{2} / \mathrm{W}$ as a thermal interfacial resistance, the actual $k_{p}$ in Equation (34) changed to another one, which is $k_{p, e f f}$ and has the form

$$
R_{f}+\frac{d_{p}}{k_{p}}=\frac{d_{p}}{k_{p, e f f}}
$$

For $\mathrm{Al}_{2} \mathrm{O}_{3}-\mathrm{H}_{2} \mathrm{O}$ and $\mathrm{CuO}-\mathrm{H}_{2} \mathrm{O}$, the function is

$$
\begin{aligned}
g^{\prime}\left(T, \phi, d_{p}\right)=\left(c_{1}+c_{2} \ln \left(d_{p}\right)\right. & \left.+c_{3} \ln (\phi)+c_{4} \ln (\phi) \ln \left(d_{p}\right)+c_{5} \ln \left(d_{p}\right)^{2}\right)+ \\
& \left(c_{6}+c_{7} \ln \left(d_{p}\right)+c_{8} \ln (\phi)+c_{9} \ln (\phi) \ln \left(d_{p}\right)+c_{10} \ln \left(d_{p}\right)^{2}\right) \ln (T),
\end{aligned}
$$

where the coefficients $c_{i}(i=1,2,3, \ldots, 10)$ are dependent on the type of nanoparticles. With $c_{i}(i=1,2,3$, ..., 10), $\mathrm{Al}_{2} \mathrm{O}_{3}-\mathrm{H}_{2} \mathrm{O}$ and CuO- $\mathrm{H}_{2} \mathrm{O}$ keep an $R^{2}$ of $96 \%$ and $98 \%$, respectively [52] (see Tables 1 and 2). The KKL(Koo-Kleinstreuer-Li) correlation becomes

$$
k_{\text {Brownian }}=5 \times 10^{4} \phi \rho_{f} C_{p, g} \sqrt{\frac{K_{b} T}{\rho_{p} d_{p}}} g^{\prime}\left(T, \phi, d_{p}\right) .
$$

Koo and Kleinstreuer [47] also analyzed the laminar motion of nanofluid in micro heat-sinks by utilizing the effective nanofluid thermal conductivity model. For the effective viscosity because of micro mixing in dispersions, they proposed:

$$
\mu_{\text {eff }}=\mu_{\text {static }}+\mu_{\text {Brownian }}=\mu_{\text {static }}+\frac{k_{\text {Brownian }}}{k_{f}} \times \frac{\mu_{f}}{(\operatorname{Pr})_{f}},
$$

where $\mu_{\text {static }}=\frac{\mu_{f}}{(1-\phi)^{2.5}}$ is the nanofluid viscosity utilized in many studies $[53,54]$. 
Table 1. Thermophysical quantities of water and nanoparticles [47].

\begin{tabular}{cccc}
\hline Thermophysical Quantities & Pure Water & $\mathbf{A l}_{2} \mathbf{O}_{3}$ & $\mathbf{C u O}$ \\
\hline$\rho\left(\mathrm{Kg} / \mathrm{m}^{3}\right)$ & 997.1 & 3970 & 6500 \\
$\mathrm{C}_{p}(\mathrm{~J} / \mathrm{KgK})$ & 4179 & 765 & 540 \\
$K(\mathrm{~W} / \mathrm{mk})$ & 0.613 & 25 & 18 \\
$\mathrm{~d}_{p}(\mathrm{~nm})$ & - & 47 & 29 \\
$\sigma(\Omega \mathrm{m})^{-1}$ & 0.05 & $10^{-12}$ & $10^{-10}$ \\
\hline
\end{tabular}

Table 2. Coefficients values of the $\mathrm{Al}_{2} \mathrm{O}_{3}-\mathrm{H}_{2} \mathrm{O}$ and $\mathrm{CuO}-\mathrm{H}_{2} \mathrm{O}$ [47].

\begin{tabular}{ccc}
\hline Coefficients Values & $\mathrm{Al}_{2} \mathbf{O}_{3}-\mathbf{H}_{2} \mathbf{O}$ & $\mathbf{C u O}-\mathbf{H}_{2} \mathbf{O}$ \\
\hline $\mathrm{c}_{1}$ & 52.813488759 & -26.593310846 \\
$\mathrm{c}_{2}$ & 6.115637295 & -0.403818333 \\
$\mathrm{c}_{3}$ & 0.6955745084 & -33.3516805 \\
$\mathrm{c}_{4}$ & $4.17455552786 \times 10^{-2}$ & 1.915825591 \\
$\mathrm{c}_{5}$ & 0.176919300241 & $6.42185846658 \times 10^{-2}$ \\
$\mathrm{c}_{6}$ & -298.19819084 & 48.40336955 \\
$\mathrm{c}_{7}$ & -34.532716906 & -9.787756683 \\
$\mathrm{c}_{8}$ & -3.9225289283 & 190.245610009 \\
$\mathrm{c}_{9}$ & -0.2354329626 & 10.9285386565 \\
$\mathrm{c}_{10}$ & -0.999063481 & -0.72009983664 \\
\hline
\end{tabular}

\section{Solution of the Problem by HAM}

Using the initial approximate values and auxiliary linear operators for the velocity and temperature fields in the following form

$$
\begin{array}{cc}
f_{0}(\zeta)=\zeta, & \theta_{0}(\zeta)=1, \\
\boldsymbol{L}_{f}=f^{\prime \prime \prime}, & \boldsymbol{L}_{\theta}=\theta^{\prime \prime},
\end{array}
$$

having the properties of operators

$$
\boldsymbol{L}_{f}\left[C_{1}+C_{2} \zeta+C_{3} \zeta^{2}\right]=0, \quad \boldsymbol{L}_{\theta}\left[C_{4}+C_{5} \zeta\right]=0
$$

with constants $C_{i}(i=1-5)$.

\subsection{Zeroth-Order Deformation Problems}

Introducing the nonlinear operators $\aleph_{f}$ and $\aleph_{\theta}$ as

$$
\begin{gathered}
\aleph_{f}[f(\zeta, p)]=\zeta \frac{\partial^{3} f(\zeta, p)}{\partial \zeta^{3}}+\frac{\partial^{2} f(\zeta, p)}{\partial \zeta^{2}}-\operatorname{Re} B_{1}(1-\phi)^{2.5}\left[\left(\frac{\partial f(\zeta, p)}{\partial \zeta}\right)^{2}-f(\zeta, p) \frac{\partial^{2} f(\zeta, p)}{\partial \zeta^{2}}\right]-M \frac{\partial f(\zeta, p)}{\partial \zeta}, \\
\aleph_{\theta}[f(\zeta, p), \theta(\zeta, p)]=\zeta \frac{\partial^{2} \theta(\zeta, p)}{\partial \zeta^{2}}+\frac{\partial \theta(\zeta, p)}{\partial \zeta}-\operatorname{Re} \operatorname{Pr}\left(\frac{B_{2}}{B_{3}}\right)\left[2 \frac{\partial f(\zeta, p)}{\partial \zeta} \theta(\zeta, p)-f(\zeta, p) \frac{\partial \theta(\zeta, p)}{\partial \zeta}\right],
\end{gathered}
$$

where $p$ is an embedding parameter such that $p \in[0,1]$.

The equations of zeroth-order deformation are prepared as

$$
\begin{gathered}
(1-p) \boldsymbol{L}_{f}\left[f(\zeta, p)-f_{0}(\zeta)\right]=p h \aleph_{f}[f(\zeta, p)], \\
(1-p) \boldsymbol{L}_{\theta}\left[\theta(\zeta, p)-\theta_{0}(\zeta)\right]=p h \aleph_{\theta}[f(\zeta, p), \theta(\zeta, p)],
\end{gathered}
$$

where $h$ is denoting the auxiliary non-zero parameter. Equation (45) has the boundary conditions

$$
f(1, p)=1, \quad f^{\prime}(1, p)=1, \quad f^{\prime}\left(\beta_{1}, p\right)=0 .
$$


The boundary conditions for Equation (46) are

$$
\begin{array}{r}
\theta(1, p)=1, \quad \theta^{\prime}\left(\beta_{1}, p\right)=0 . \\
p=0 \Rightarrow f(\zeta, 0)=f_{0}(\zeta) \quad \text { and } \quad p=1 \Rightarrow f(\zeta, 1)=f(\zeta), \\
p=0 \Rightarrow \theta(\zeta, 0)=\theta_{0}(\zeta) \quad \text { and } \quad p=1 \Rightarrow \theta(\zeta, 1)=\theta(\zeta),
\end{array}
$$

$f(\zeta, p)$ becomes $f_{0}(\zeta)$ to $f(\zeta)$ when $p$ assumes the values from 0 to 1 . Similarly, $\theta(\zeta, p)$ becomes $\theta_{0}(\zeta)$ to $\theta(\zeta)$ when $p$ assumes the values from 0 to 1 . Using Taylor series expansion and Equations (45) and (46), one obtains

$$
\begin{gathered}
f(\zeta, p)=f_{0}(\zeta)+\sum_{m=1}^{\infty} f_{m}(\zeta) p^{m}, \quad f_{m}(\zeta)=\left.\frac{1}{m !} \frac{\partial^{m} f(\zeta, p)}{\partial p^{m}}\right|_{p=0} \\
\theta(\zeta, p)=\theta_{0}(\zeta)+\sum_{m=1}^{\infty} \theta_{m}(\zeta) p^{m}, \quad \theta_{m}(\zeta)=\left.\frac{1}{m !} \frac{\partial^{m} \theta(\zeta, p)}{\partial p^{m}}\right|_{p=0} .
\end{gathered}
$$

The convergence of the series is sharply relying on $h$. Suppose $h$ is taken by choice in a such type that the series converges at $p=1$, so Equations (51) and (52) result in

$$
\begin{aligned}
& f(\zeta)=f_{0}(\zeta)+\sum_{m=1}^{\infty} f_{m}(\zeta) \\
& \theta(\zeta)=\theta_{0}(\zeta)+\sum_{m=1}^{\infty} \theta_{m}(\zeta)
\end{aligned}
$$

\section{2. m-th Order Deformation Problems}

By taking $m$ times derivative with respect to $p$ of Equations (45) and (47) then dividing by $m$ ! and substituting $p=0$, yield the below simplifications

$$
\begin{gathered}
\boldsymbol{L}_{f}\left[f_{m}(\zeta)-\chi_{m} f_{m-1}(\zeta)\right]=h R_{m}^{f}(\zeta), \\
f_{m}(1)=f_{m}^{\prime}(1)=f_{m}^{\prime \prime}\left(\beta_{1}\right)=0, \\
R_{m}^{f}(\zeta)=\zeta f_{m-1}^{\prime \prime \prime}+f_{m-1}^{\prime \prime}-\operatorname{Re} B_{1}(1-\phi)^{2.5} \sum_{k=0}^{m-1}\left[f_{m-1-k}^{\prime} f_{k}^{\prime}-f_{m-1-k} f_{k}^{\prime \prime}\right]-M f_{m-1}^{\prime} .
\end{gathered}
$$

By taking $m$ times derivative with respect to $p$ of Equatoins (46) and (48), then dividing by $m$ ! and substituting $p=0$, yield the below simplifications

$$
\begin{gathered}
\boldsymbol{L}_{\theta}\left[\theta_{m}(\zeta)-\chi_{m} \theta_{m-1}(\zeta)\right]=h R_{m}^{\theta}(\zeta), \\
\theta_{m}(1)=\theta_{m}^{\prime}\left(\beta_{1}\right)=0, \\
R_{m}^{\theta}(\zeta)=\zeta \theta_{m-1}^{\prime \prime}+\theta_{m-1}^{\prime}-\operatorname{Re} \operatorname{Pr}\left(\frac{B_{2}}{B_{3}}\right)\left[2 f_{m-1-k}^{\prime} \theta_{k}-f_{m-1-k} \theta_{k}^{\prime}\right], \\
\chi_{m}= \begin{cases}0, & m \leq 1 \\
1, & m>1 .\end{cases}
\end{gathered}
$$

If $f_{m}^{*}(\zeta)$ and $\theta_{m}^{*}(\zeta)$ are the particular solutions, then the general solutions of Equations (55) and (58) in terms of special solutions are represented as follows:

$$
\begin{gathered}
f_{m}(\zeta)=f_{m}^{*}(\zeta)+C_{1}+C_{2} \zeta+C_{3} \zeta^{2} \\
\theta_{m}(\zeta)=\theta_{m}^{*}(\zeta)+C_{4}+C_{5} \zeta
\end{gathered}
$$




\section{Results and Discussion}

The Equations (11) and (12) with boundary conditions in Equations (13) and (14) are evaluated by the symbolic computer application MATHEMATICA using HAM program and Equation (19) is computed through HAM solution. It is interested to describe the impact of all the parameters on the non-dimensional velocity profile $f(\zeta)$, temperature distribution $\theta(\zeta)$ and pressure distribution $\frac{P-P_{\infty}}{c \mu_{n f}}(\zeta)$. The rate of spray $m_{2}\left(\beta_{1}\right)$ is also discussed. The geometry of the problem is shown in Figure 1. Liao [55-57] introduced $h$ curves for the convergence of the series solution to get the acceptable results of the problems. Therefore, the acceptable $h$-curves for $f(\zeta)$ and $\theta(\zeta)$ are drawn in the ranges $-2.30 \leq h \leq-0.50$ and $-2.50 \leq h \leq 0.50$ in Figures 2 and 3 respectively. The fact is known about the shear stress and rate of transfer of heat that they depend on the types of nanofluids. The type of the nanofluid has a direct relation with cooling and heating techniques. These qualities are achieved easily and quickly by choosing $\mathrm{CuO}$ as nanoparticles compared to $\mathrm{Al}_{2} \mathrm{O}_{3}$ as nanoparticles. In this research $\mathrm{CuO}-\mathrm{H}_{2} \mathrm{O}$ is used to elaborate the impact of indispensable parameters.

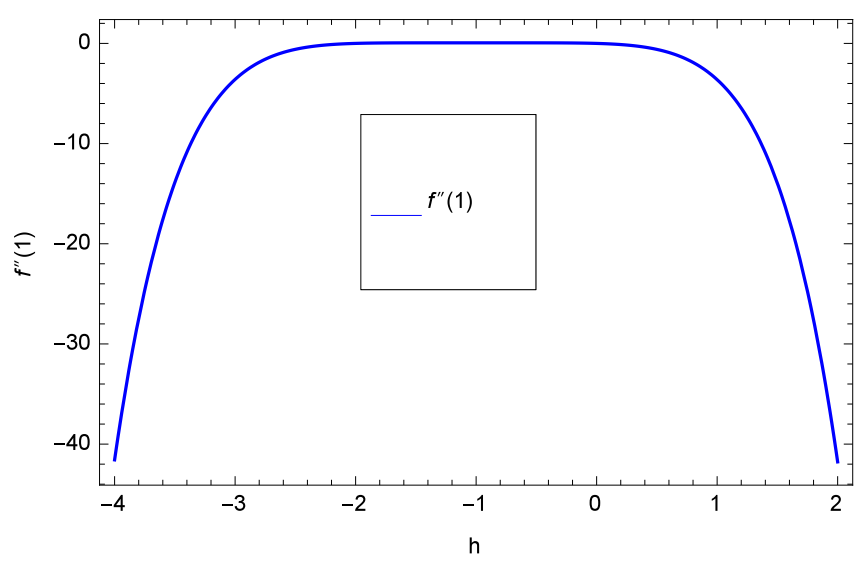

Figure 2. $h$ curve of $f(\zeta)$.

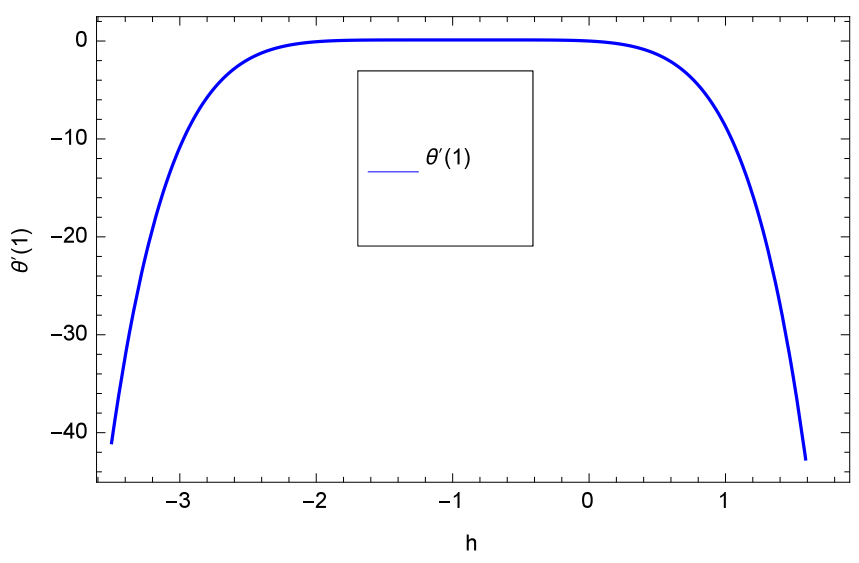

Figure 3. $h$ curve of $\theta(\zeta)$.

\section{Discussion}

\subsection{Velocity Profile}

It is elucidated that motion of the fluid slows down near the stretching surface and it enhances far away from stretching cylinder. The salient characters in the film sprayed on a cylinder are the 
thin film nanofluid parameter $\beta_{1}$ and the stretching Reynolds number Re. Concentrating first the contribution of the thin film nanofluid parameter $\beta_{1}$, which has the close relation to the rate of mass spray. It affects the flow behavior completely. From Figure 4 , it is evident that the velocity faces retardation with greater quantities of film thickness parameter $\beta_{1}$. The axial velocity $f(\zeta)$ is found to enhance with thinning of the nanoliquid film. With the increase of film thickness the mass of the fluid increases which is difficult to move. Motion automatically stops when thickness of the fluid film is high. Too much effort is required for the movement of the thick film liquid. It is very difficult to make motion in the sea compared to the flow in a pipe. The nanoparticle volume fraction parameter $\phi$ has a negligible effect on the motion witnessed by Figure 5 . Velocity does not change with increasing values of $\phi$. Figure 6 demonstrates that the axial velocity $f(\zeta)$ goes to decrease by the large values of Reynolds number $R e$. The reason is that the Reynolds number is the ratio of the inertia force to the viscous force so, when the Reynolds number becomes higher the inertial force overcomes the flow in contrast to viscous forces. Hence for the greater values of Reynolds number Re velocity retards and the motion decays gradually to the ambient. The inertial forces are very powerful and they do not allow the liquid atoms/molecules to flow. Strong viscous forces have strong resistance to the motion of the fluid. Boundary layer flow of fluid motion decreases with strong inertial forces. Figure 7 is prepared for the parameter $M$ demonstrating magnetic field. As the values of $M$ increases on surface during the flow, the motion decreases which results in to retard the motion profiles. Generally, the momentum boundary layer is made thin by greater quantities of $M$ since the use of magnetic field to a fluid capable for conduction generates a force of resistivity called Lorentz force. This force is responsible for bringing the retardation in the movement of the fluid. This force decelerates the motion horizontally and overcomes the motion layer related to axial velocity $f(\zeta)$. This characteristic remains up to some heights and then the action is converted to slowing down. The magnetic field parameter keeps an additional influence on the motion. It is clear that magnetic field produces more restriction to the fluid. In fact, magnetic field is in contrast to the transportation.

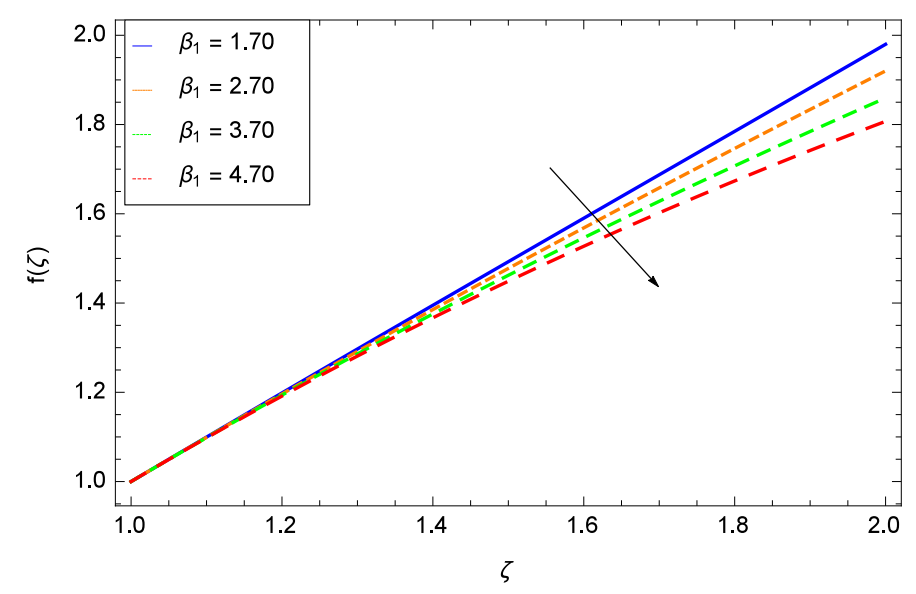

Figure 4. Non-dimensional velocity $f(\zeta)$ sketch for $h=-0.10, M=0.10, \operatorname{Re}=0.70, \phi=0.04, \operatorname{Pr}=6.80$ and various values of $\beta_{1}\left(\mathrm{CuO}-\mathrm{H}_{2} \mathrm{O}\right)$. 


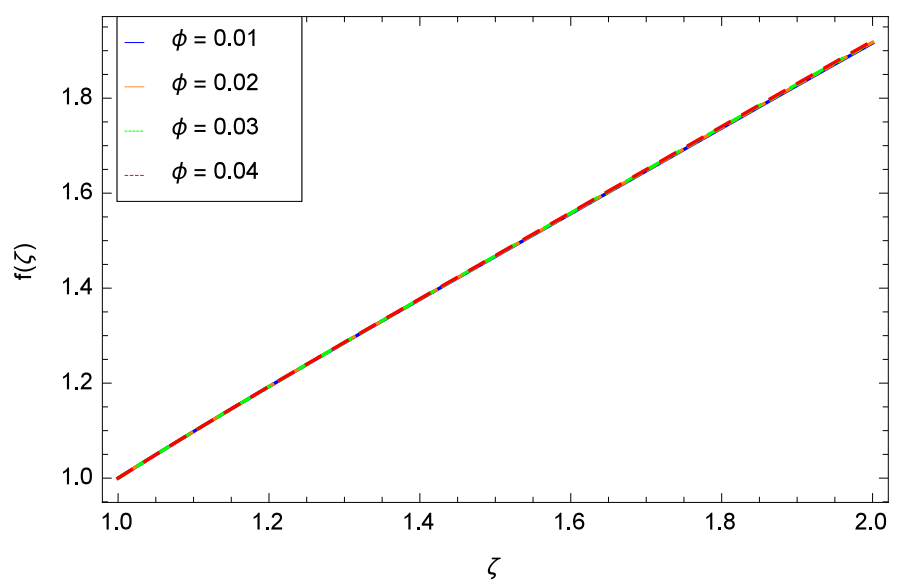

Figure 5. Non-dimensional velocity $f(\zeta)$ sketch for $h=-1.10, \beta_{1}=1.70, M=0.10, \operatorname{Re}=0.70, \operatorname{Pr}=6.80$ and various values of $\phi\left(\mathrm{CuO}-\mathrm{H}_{2} \mathrm{O}\right)$.

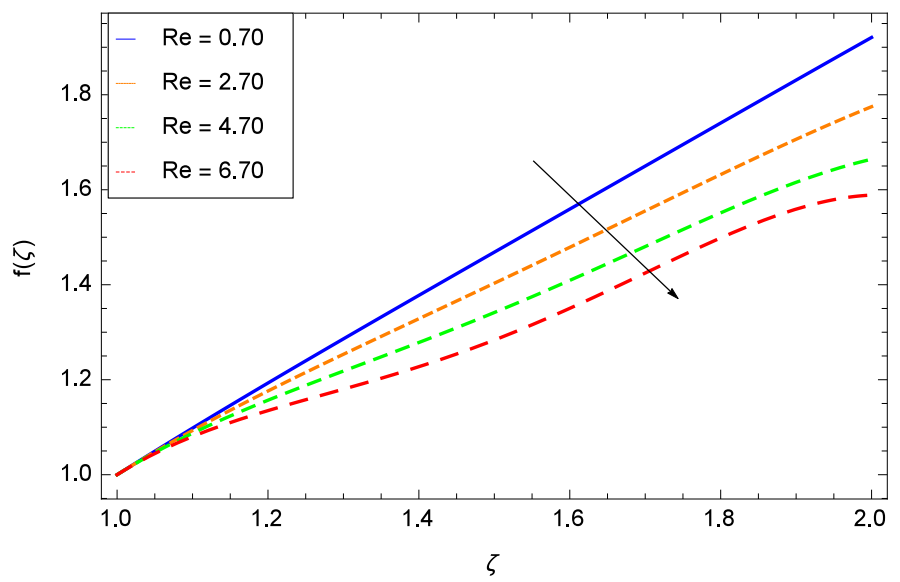

Figure 6. Non-dimensional velocity $f(\zeta)$ sketch for $h=-1.10, \beta_{1}=1.70, M=0.10, \phi=0.04, \operatorname{Pr}=6.80$ and greater quantities of $\operatorname{Re}\left(\mathrm{CuO}-\mathrm{H}_{2} \mathrm{O}\right)$.

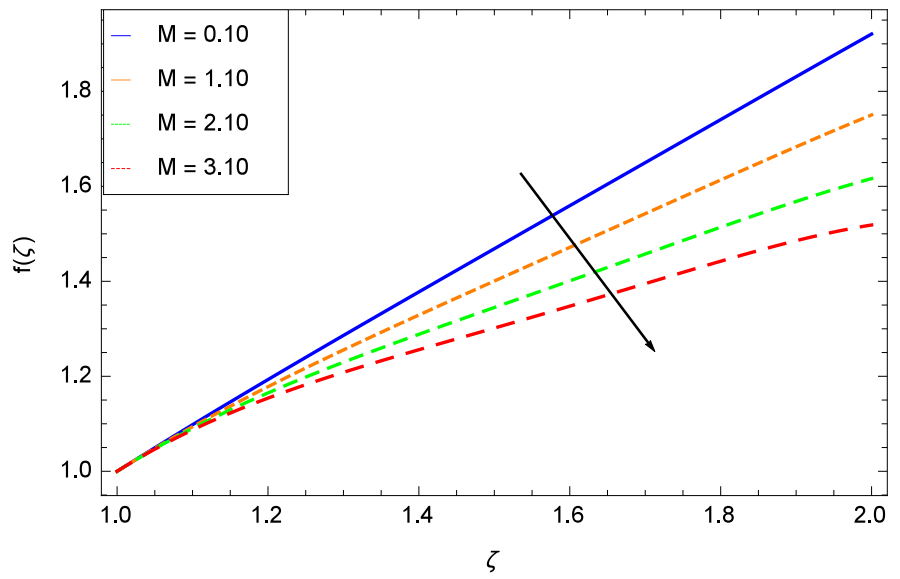

Figure 7. Non-dimensional velocity $f(\zeta)$ sketch for $h=-1.10, \beta_{1}=1.70, M=0.10, \operatorname{Re}=0.70, \phi=0.04$, $\operatorname{Pr}=6.80$ and greater quantities of $\mathrm{M}\left(\mathrm{CuO}-\mathrm{H}_{2} \mathrm{O}\right)$. 


\subsection{Temperature Profile}

The thermal investigation has a prominent application in the cooling of the cylinder. The thin film parameter $\beta_{1}$ has a special role in the temperature distribution. The non-dimensional temperature $\theta(\zeta)$ is high at the surface and it is growing small along the transversely distance within the thermal boundary layer. The dimensional temperature $\theta(\zeta)$ decelerates for greater quantities of film thickness parameter $\beta_{1}$ which is obvious in Figure 8. Transfer of heat is improved for the thinning of the nanofluid film. But in the present case, it is depreciating. The reason is that with the thickness of the fluid film the mass of the fluid is greater which exhaust the amount of temperature. Heat penetrates in the fluid as a result the environment is cool down. Thick film fluid needs more heat as compared to the thin film fluid. The volume fraction parameter $\phi$ is displayed in Figure 9. No sensitivity occurs in temperature for greater quantities of the volume fraction parameter $\phi$. Figure 10 predicts that the temperature $\theta(\zeta)$ depreciates for the big quantities of Reynolds number $R e$. It is due to the fact that greater Reynolds number signifies that inertial forces exist as the overcoming agents in contrasting the the viscous forces. These inertial forces are very powerful and due to these forces the particles (atoms and molecules) of the fluid remains tightly. Too much heat energy is required in order to break down the bonds between atoms and molecules of the fluids. Due to these forces the boiling point of fluids increase. Figure 11 indicates that temperature distribution enhances with various values of magnetic field parameter $M$. Due to the application of magnetic the Lorentz force is generated which increases the temperature of the fluid. This force supports and favors the temperature. Since the magnetic field is imposed perpendicularly so with the increasing magnetic field effect the fluid is controlled and bounded. Figure 12 witnesses the influence of Prandtl number $P r$ describing that $\theta(\zeta)$ decreases with larger values of $\operatorname{Pr}$ since for the larger quantities of $\operatorname{Pr}$ the thermal boundary layer decreases which displays that effective cooling is achieved quickly for nanofluid. The influence is even more clear for high Prandtl number because the motion layer size is comparatively small. For the greater quantities of $P r$ the liquid keeps low thermal conductivity which causes thinner thermal boundary layer resulting in the enhancement of the rate of transfer of heat at the surface. Prandtl number defines the ratio of momentum diffusivity to thermal diffusivity. Those liquids which have minimum Prandtl number have good thermal conductivity consequently, possess thick boundary layer structures for diffusing heat.

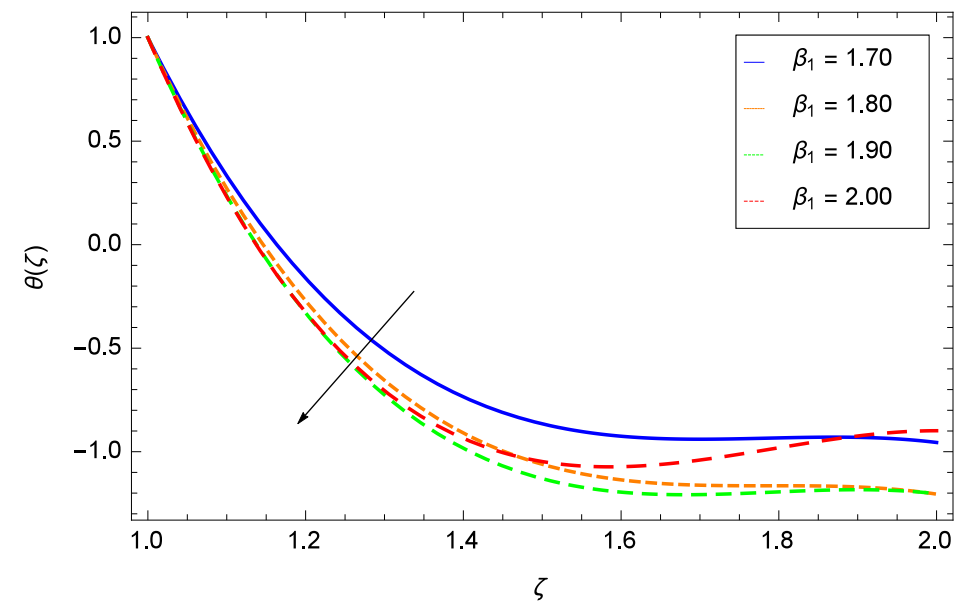

Figure 8. Non-dimensional temperature $\theta(\zeta)$ sketch for $h=-0.10, M=2.00, \operatorname{Re}=5.00, \phi=0.04$, $\operatorname{Pr}=6.80$ and various values of $\beta_{1}\left(\mathrm{CuO}-\mathrm{H}_{2} \mathrm{O}\right)$. 


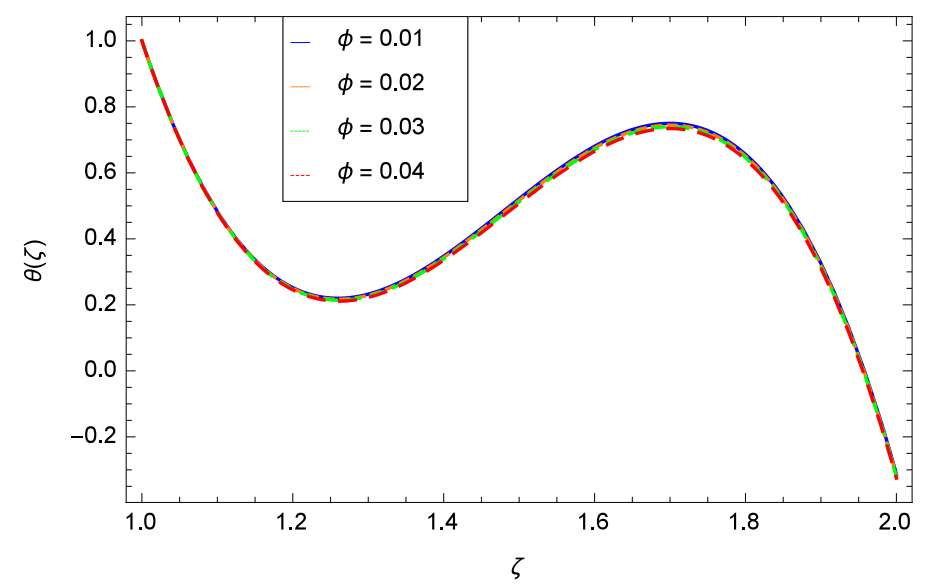

Figure 9. Non-dimensional temperature $\theta(\zeta)$ sketch for $h=-1.10, \beta_{1}=1.70, M=0.10, \operatorname{Re}=0.70$, $\operatorname{Pr}=6.80$ and various values of $\phi\left(\mathrm{CuO}-\mathrm{H}_{2} \mathrm{O}\right)$.

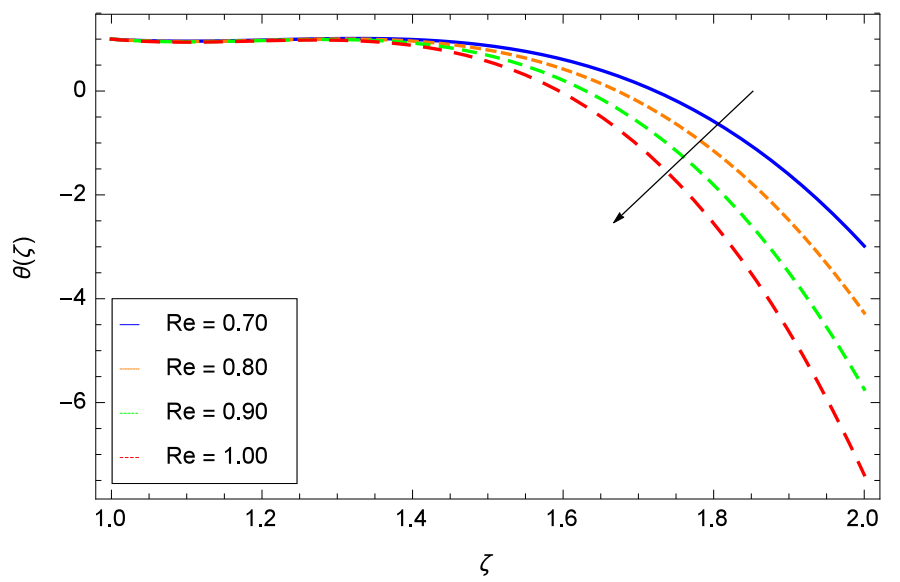

Figure 10. Non-dimensional temperature $\theta(\zeta)$ sketch for $h=-1.10, \beta_{1}=1.10, \phi=0.04, M=0.10$, $\operatorname{Pr}=6.80$ and greater quantities of $\operatorname{Re}\left(\mathrm{CuO}-\mathrm{H}_{2} \mathrm{O}\right)$.

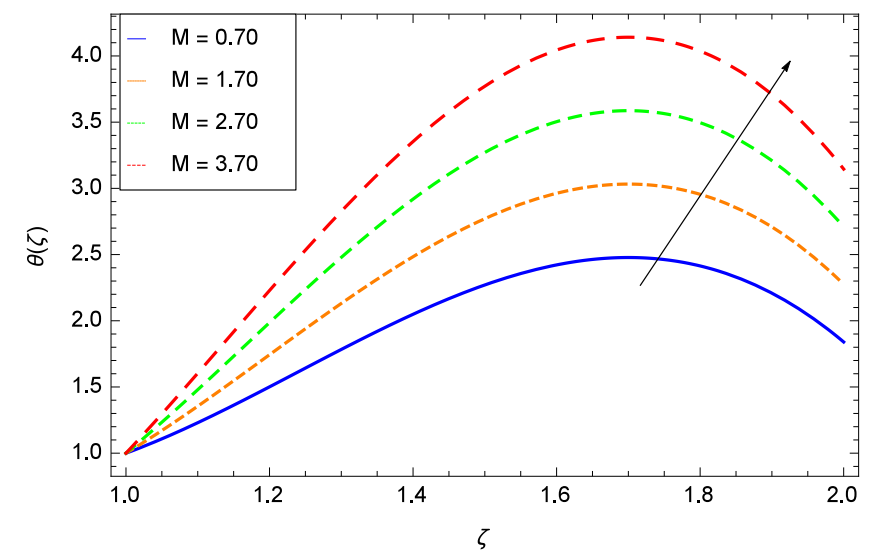

Figure 11. Non-dimensional temperature $\theta(\zeta)$ sketch for $h=-2.50, \beta_{1}=1.70, \phi=0.04, M=0.10$, $\mathrm{Pr}=6.80$ and greater quantities of $\mathrm{M}\left(\mathrm{CuO}-\mathrm{H}_{2} \mathrm{O}\right)$. 


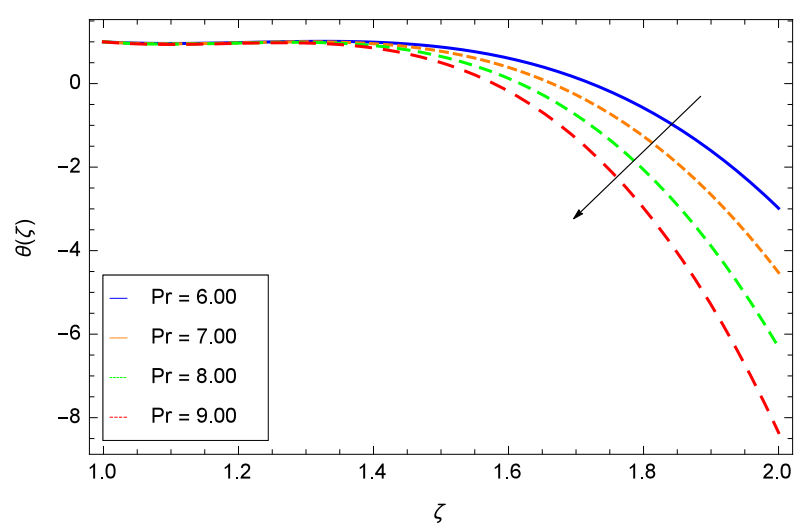

Figure 12. Non-dimensional temperature $\theta(\zeta)$ sketch for $h=-1.10, \beta_{1}=1.10, M=0.10, \phi=0.04$, $\operatorname{Re}=0.70$ and various values of $\operatorname{Pr}\left(\mathrm{CuO}-\mathrm{H}_{2} \mathrm{O}\right)$.

\subsection{Pressure Distribution}

This section describes the characteristics of pressure $\frac{P-P_{\infty}}{c \mu_{n f}}(\zeta)$ in terms of various parameters. Pressure has important contribution in fluid motion and blood flow. Blood circulates in the veins due to pressure. In atmosphere, pressure is inevitable to exist. There are so many machines working due to pressure. Figure 13 indicates that pressure enhances for the greater values of thin film parameter $\beta_{1}$. Pressure distribution is less in magnitude in the wider part of the channel of the motion. The pressure becomes strong with the greater size of film and more power is required to overcome the stress generated due to the thickness of film. The pressure and the film thickness posses a huge force in joint collaboration. This force is very important and is used to help in moving the vehicles/objects over water, in windmills when the fluid flow and objects motion are in the same direction otherwise this force opposes the motion (in case of opposite directions) of the bodies/boats/ships. Figure 14 demonstrates that with the rise of volume fraction parameter $\phi$ the pressure distribution $\frac{P-P_{\infty}}{c \mu_{n f}}(\zeta)$ rises because with the addition of nanoparticles the concentration increases, consequently the pressure enhances. When the concentration increases then the fluid becomes thick as a result collision of atoms/molecules increase and exert a great pressure with one another and on the walls of vessel. This characteristic of fluid is very useful for blood flow and for the concentration in medicine. Thick blood runs fast in moving down through pipe due to pressure when injected to the patient. Apart from this, almost all the chemical reactions are made at high pressure. At high pressure, cooking is done easily compared to low pressure. The pressure distribution $\frac{P-P_{\infty}}{c \mu_{n f}}(\zeta)$ reduces with greater quantities of Reynolds number $R e$ as it is depicted by Figure 15. Pressure automatically goes to minimum value in the wider way of motion due to inertial effects. Due to inertial forces the particles of the fluids are packed tightly and firmly and high pressure is required to make motion from the rest. Pressure has no effect on these attractive forces. High pressure is required to overcome these intermolecular forces. The impact of magnetic parameter $M$ lies in Figure 16. It states that pressure distribution $\frac{P-P_{\infty}}{c \mu_{n f}}(\zeta)$ is low due to the Lorentz force in the wider channel of the flow. The magnetic is applied perpendicular to the flow of fluid. Lorentz force capture the fluid in the boundary layer. To compete the Lorentz force due to strong magnetic field, pressure must be high in order to make the motion of the fluid. 


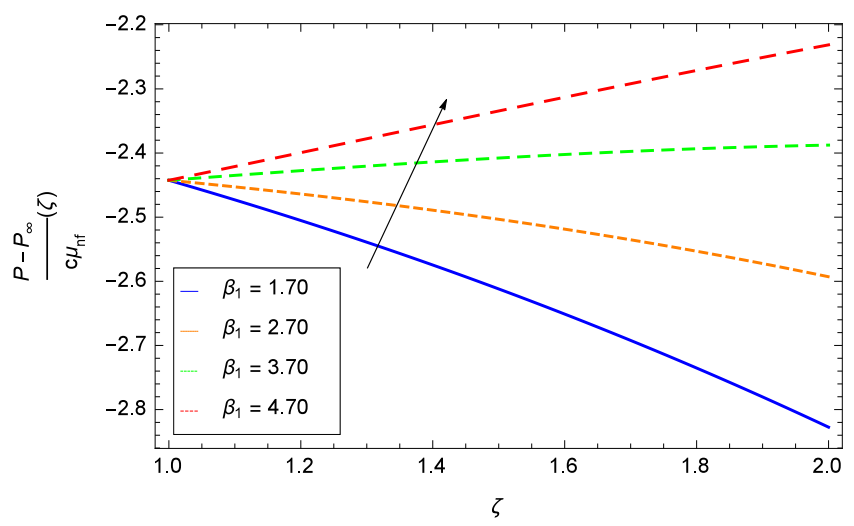

Figure 13. Non-dimensional Pressure $\frac{P-P_{\infty}}{c \mu_{n f}}(\zeta)$ sketch for $h=-0.10, M=0.10, \operatorname{Re}=0.70, \phi=0.04$, $\operatorname{Pr}=6.80$ and various values of $\beta_{1}\left(\mathrm{CuO}-\mathrm{H}_{2} \mathrm{O}\right)$.

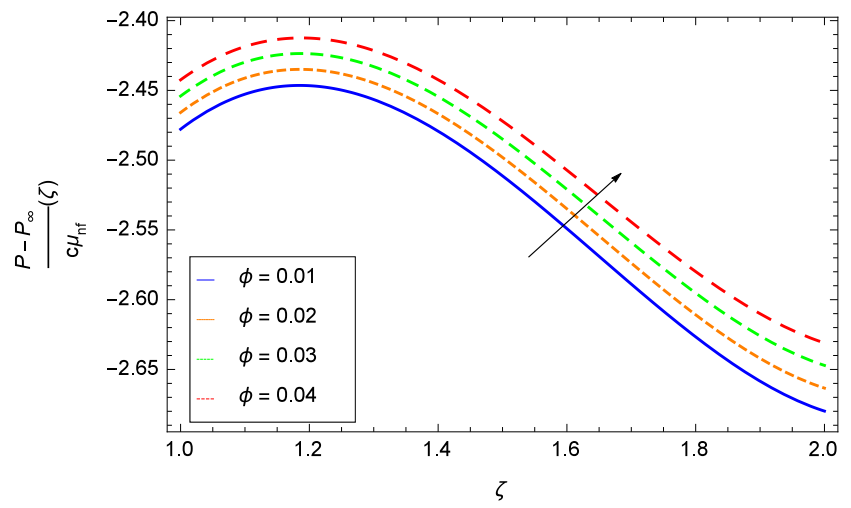

Figure 14. Non-dimensional Pressure $\frac{P-P_{\infty}}{c \mu_{n f}}(\zeta)$ sketch for $h=-1.10, \beta_{1}=1.70, M=0.10, R e=0.70$, $\operatorname{Pr}=6.80$ and various values of $\phi\left(\mathrm{CuO}-\mathrm{H}_{2} \mathrm{O}\right)$.

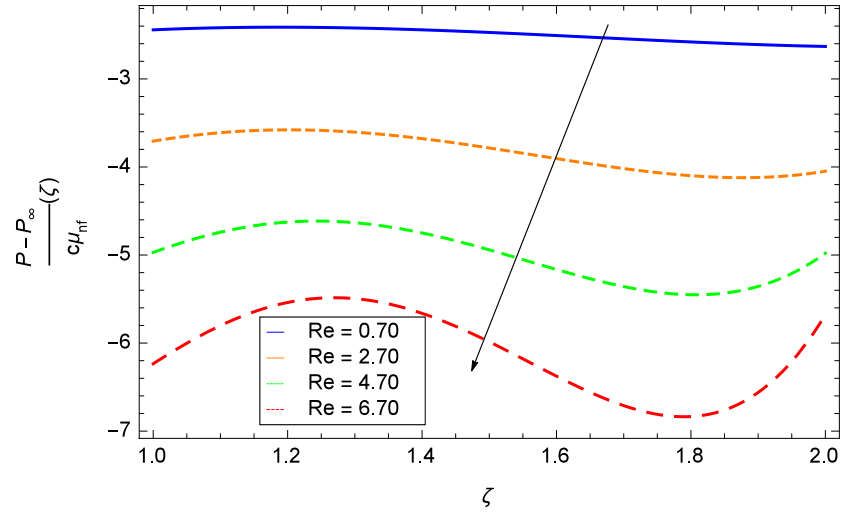

Figure 15. Non-dimensional Pressure $\frac{P-P_{\infty}}{c \mu_{n f}}(\zeta)$ sketch for $h=-1.10, \beta_{1}=1.70, M=0.10, \phi=0.04$, $\mathrm{Pr}=6.80$ and greater quantities of $\operatorname{Re}\left(\mathrm{CuO}-\mathrm{H}_{2} \mathrm{O}\right)$. 


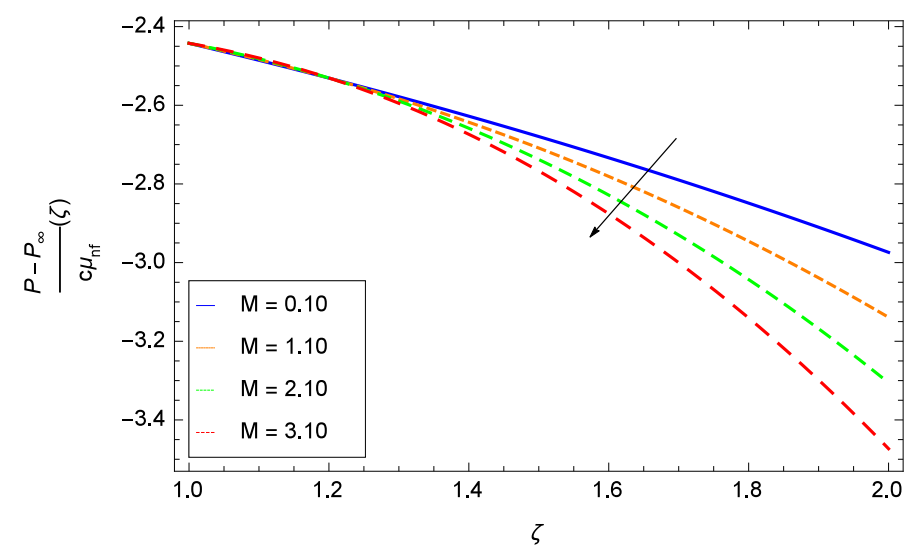

Figure 16. Non-dimensional Pressure $\frac{P-P_{\infty}}{c \mu_{n f}}(\zeta)$ sketch for $h=-0.10, \beta_{1}=1.70, M=0.10, R e=0.70$, $\phi=0.04, \operatorname{Pr}=6.80$ and greater quantities of $M\left(\mathrm{CuO}-\mathrm{H}_{2} \mathrm{O}\right)$.

\subsection{Spray Distribution}

A stretching cylinder is sprayed by a nanoliquid $\mathrm{CuO}-\mathrm{H}_{2} \mathrm{O}$ as a coolant and protecting paint or film. Figure 17 expresses the normalized spray rate $m_{2}$ which is related functionally to the film size $\beta_{1}$. It is evident that the film size enhances at once by the rate of spray, but it does not occur linearly. If the deposition spray is not uniform, then it is possible to affect the film outer surface.

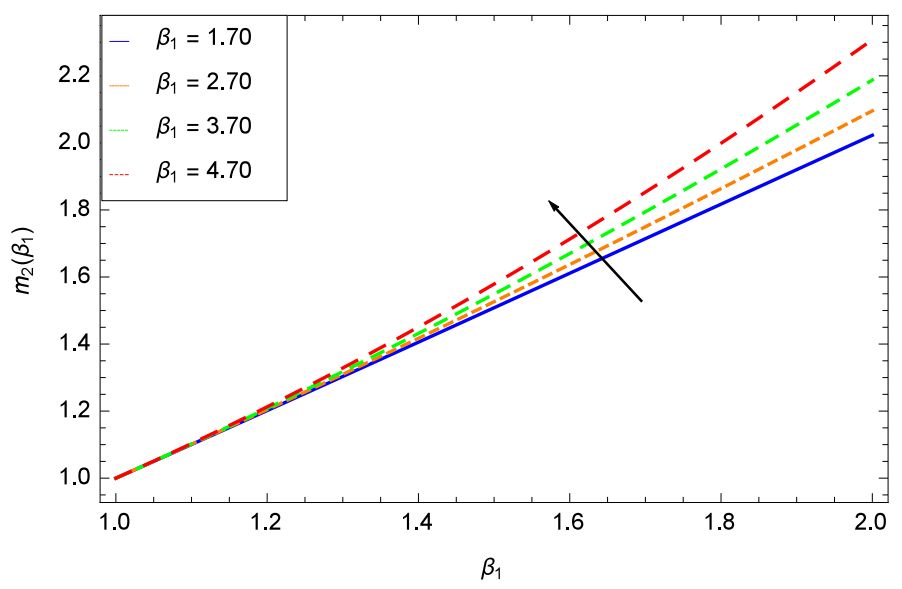

Figure 17. Rate of spray $m_{2}\left(\beta_{1}\right)$ sketch for $h=0.10, M=0.10, \operatorname{Re}=0.70, \phi=0.04, \operatorname{Pr}=6.80$ and various values of $\beta_{1}\left(\mathrm{CuO}-\mathrm{H}_{2} \mathrm{O}\right)$.

\subsection{Numerical Comparison, Residual Error Sketches and Tables}

In order to obtain the accuracy of the achieved results a proper mechanism is adopted. HAM solution is compared with the numerical method solution which shows an excellent agreement with one another. In Figures 18 and 19 the HAM solution graphs of velocity and temperature overlap with the graphs of numerical method solution. To be more authentic the HAM solution, the residual error Res graphs are drawn in Figures 20 and 21. Similarly to achieve more precision of HAM solution the comparison Table of HAM solution and numerical method solution is prepared in Table 3. The residual error Table 4 also shows the accuracy of results numerically. 


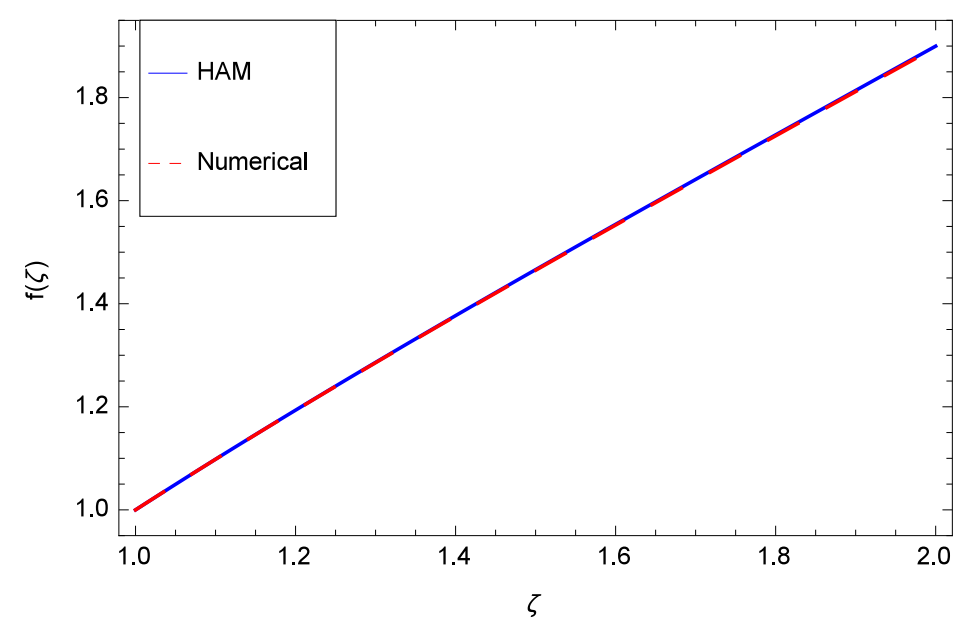

Figure 18. Comparison of the velocity solution of HAM with numerical method solution when $h=-0.55, \beta_{1}=2.00, M=0.10, \operatorname{Re}=0.70, \phi=0.04, \operatorname{Pr}=1.10$ for $\left(\mathrm{CuO}-\mathrm{H}_{2} \mathrm{O}\right)$.

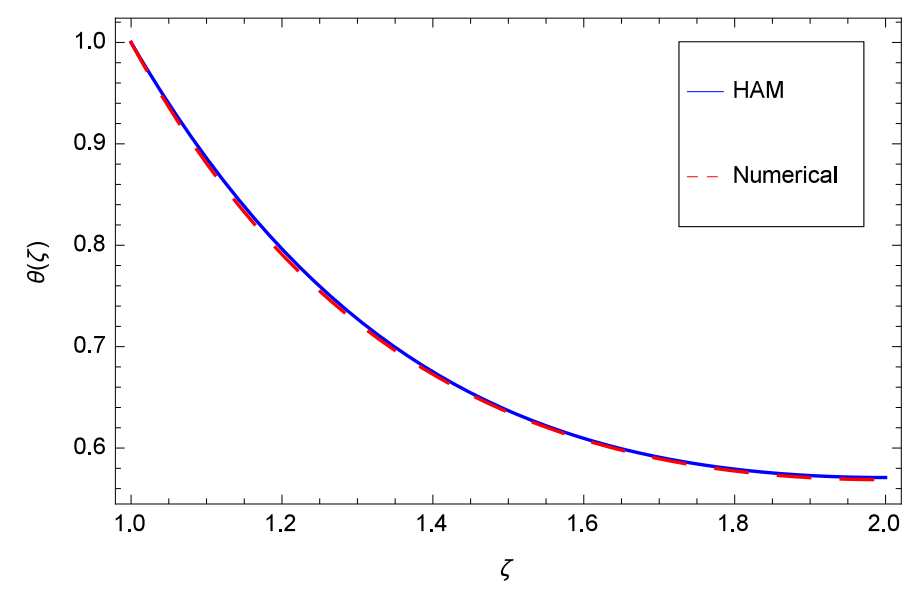

Figure 19. Comparison of the temperature solution of HAM with numerical method solution when $h=-0.55, \beta_{1}=2.00, M=0.10, \operatorname{Re}=0.70, \phi=0.04, \operatorname{Pr}=1.10$ for $\left(\mathrm{CuO}-\mathrm{H}_{2} \mathrm{O}\right)$.

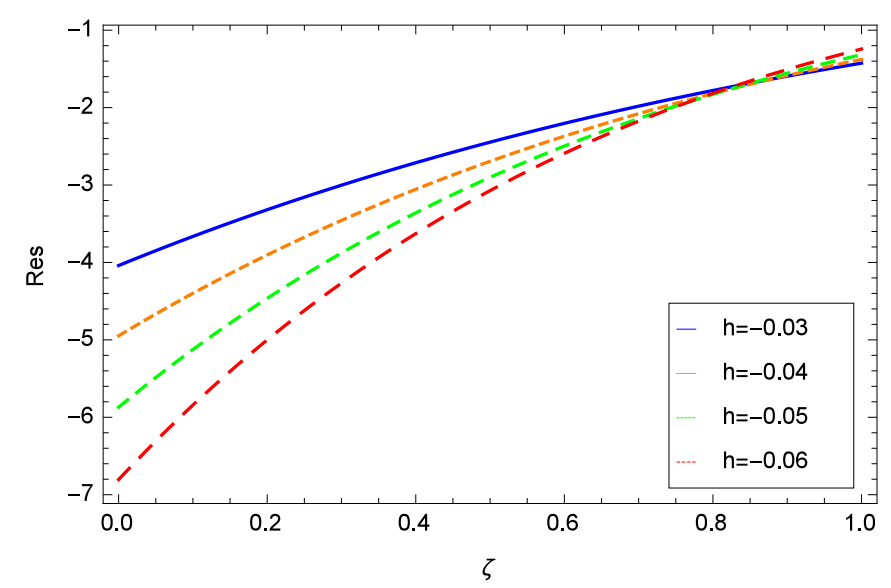

Figure 20. Residual errors sketch of the velocity solution of HAM when $\beta_{1}=2.00, M=0.10, R e=0.70$, $\phi=0.04, \mathrm{Pr}=1.10$ and various values of $h$ for $\left(\mathrm{CuO}-\mathrm{H}_{2} \mathrm{O}\right)$. 


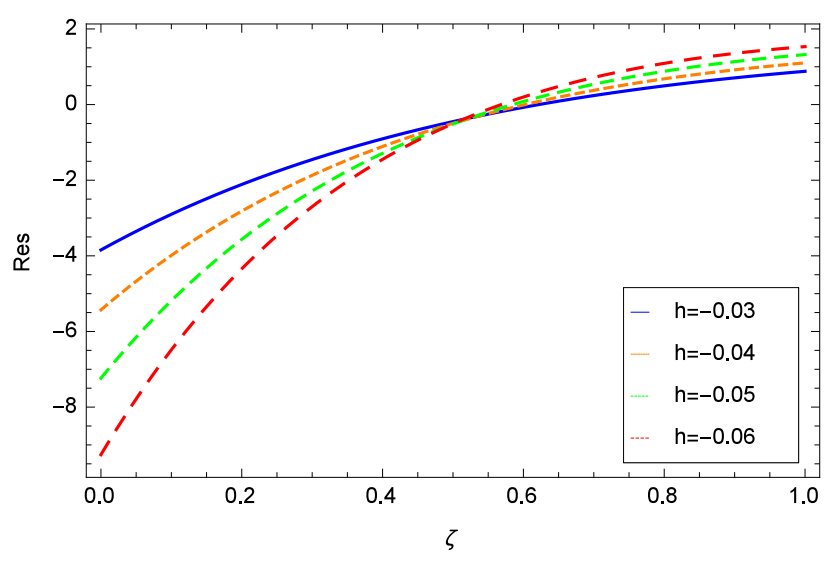

Figure 21. Residual errors sketch of the temperature solution of HAM when $\beta_{1}=2.00, M=0.10$, $\operatorname{Re}=0.70, \phi=0.04, \operatorname{Pr}=1.10$ and various values of $h$ for $\left(\mathrm{CuO}-\mathrm{H}_{2} \mathrm{O}\right)$.

Table 3. Comparison of solution of HAM with numerical method solution.

\begin{tabular}{cccccccc}
\hline & \multicolumn{3}{c}{ Velocity } & \multicolumn{5}{c}{ Temperature } \\
\hline $\boldsymbol{\zeta}$ & $\boldsymbol{f ( \zeta )}$ & Numerical Values & Errors & $\boldsymbol{\zeta}$ & $\boldsymbol{\theta}(\zeta)$ & Numerical Values & Errors \\
\hline 0.0 & 1. & 1. & $-4.44089 \times 10^{-16}$ & 0.0 & 1.0 & 1.0 & $-6.30818 \times 10^{-8}$ \\
0.1 & 1.09826 & 1.09814 & 0.000124947 & 0.1 & 0.885877 & 0.880696 & 0.00518123 \\
0.2 & 1.19347 & 1.19308 & 0.000389778 & 0.2 & 0.7963263 & 0.79091 & 0.00541687 \\
0.3 & 1.2862 & 1.28551 & 0.000692582 & 0.3 & 0.7273 & 0.723303 & 0.00399767 \\
0.4 & 1.37694 & 1.37595 & 0.000987247 & 0.4 & 0.675195 & 0.672662 & 0.00253345 \\
0.5 & 1.46611 & 1.46485 & 0.0012588 & 0.5 & 0.636847 & 0.635206 & 0.00164092 \\
0.6 & 1.5541 & 1.55259 & 0.00150777 & 0.6 & 0.609527 & 0.608145 & 0.00138164 \\
0.7 & 1.64121 & 1.63947 & 0.0017406 & 0.7 & 0.590937 & 0.589388 & 0.00154869 \\
0.8 & 1.72772 & 1.72575 & 0.00196426 & 0.8 & 0.579203 & 0.577345 & 0.00185881 \\
0.9 & 1.81386 & 1.81167 & 0.00218373 & 0.9 & 0.572877 & 0.570793 & 0.002084 \\
1.0 & 1.89982 & 1.89742 & 0.00240171 & 1.0 & 0.570928 & 0.568784 & 0.00214339 \\
\hline
\end{tabular}

Table 4. Results achieved by HAM and Residual Errors.

\begin{tabular}{cccccc}
\hline \multicolumn{2}{c}{ Velocity } & \multicolumn{2}{c}{ Temperature } \\
\hline$\zeta$ & $f(\zeta)$ & Residual Errors & $\zeta$ & $\boldsymbol{\theta}(\zeta)$ & Residual Errors \\
\hline 0.0 & 1. & -0.64363 & 0.0 & 1.0 & 1.53209 \\
0.1 & 1.09667 & -0.456915 & 0.1 & 0.931831 & 1.64776 \\
0.2 & 1.18735 & -0.29789 & 0.2 & 0.875176 & 1.71672 \\
0.3 & 1.27298 & -0.162766 & 0.3 & 0.828685 & 1.75179 \\
0.4 & 1.35444 & -0.0481967 & 0.4 & 0.791164 & 1.76305 \\
0.5 & 1.43248 & 0.0487658 & 0.5 & 0.761557 & 1.75834 \\
0.6 & 1.50783 & 0.130716 & 0.6 & 0.738932 & 1.74376 \\
0.7 & 1.58112 & 0.199934 & 0.7 & 0.722468 & 1.72407 \\
0.8 & 1.65293 & 0.258415 & 0.8 & 0.711444 & 1.70297 \\
0.9 & 1.72381 & 0.307909 & 0.9 & 0.705227 & 1.6833 \\
1.0 & 1.79423 & 0.349941 & 1.0 & 0.703266 & 1.6673 \\
\hline
\end{tabular}

5.6. Skin Friction Coefficient $\left(C_{f}\right)$, Nusselt Number (Nu) Sketches and Tables Showing Comparison with the Published Experimental Work

It is experimental proved that the shear stress and rate of heat transfer change by using different kinds of nanofluids. From this, it is concluded that the type of nanofluid is most important in the cooling and heating processes. By selecting $\mathrm{CuO}$ as nanoparticle the higher Nusselt number and smaller skin friction coefficient can be achieved. Therefore in the present study $\mathrm{CuO}-\mathrm{H}_{2} \mathrm{O}$ is used to investigate the effects of various parameters. The thermo-physical properties of the nanoliquid are taken to be functions of the volume fraction and the thermal conductivity is modeled based on the effective medium theory. The Prandtl number $\operatorname{Pr}$ for the base liquid water is usually around 7 . Using 
the definition of Prandtl number and the thermo-physical properties of water as listed in Table 1 along with $\mu_{f}=1 \times 10^{-3} \mathrm{~Pa} \mathrm{~s}$ at $20^{\circ} \mathrm{C}$, the Prandtl number of water is evaluated to be $\operatorname{Pr}=6.8173$. This value has been used throughout the computations.

Effects of $\mathrm{CuO}-\mathrm{H}_{2} \mathrm{O}$ nanofluid on skin friction coefficient $\left(\mathrm{C}_{f}\right)$ and Nusselt number $(\mathrm{Nu})$ are demonstrated in Figures 22 and 23. The quantity $C_{f}$ related to the surface drag is shown as a function of the Reynolds number Re for different values of $\phi$. Figure 22 presents the scenario that the skin friction coefficient $\left(C_{f}\right)$ decreases with the increase of nanoparticle volume fraction $\phi$. Figure 23 highlights the effect of nanoparticle volume fraction $\phi$ on Nusselt number $N u$ as a increasing function of Reynolds number $R e$. The reason is that the inclusion of nano-sized particles in water like cooling liquids greatly enhances their thermal conductivity thereby causing an increase in the heat transfer rates. The significant variation in Nusselt number against volume fraction in case of $\mathrm{CuO}-\mathrm{H}_{2} \mathrm{O}$ is observed. The type of nanofluid is a key factor for heat transfer enhancement. The higher values of Nusselt number are obtained by selecting $\mathrm{CuO}$ nano-sized particles. Tables 5 and 6 show the comparison of the effects of different kinds of nanoparticles on skin friction coefficient $\left(C_{f}\right)$ and Nusselt number $(\mathrm{Nu})$ in terms of various values of Reynolds number $R e$ against the variation of volume fraction $\phi$. Both the Tables numerically show the published experimental results and the present study results which show an excellent correlation.

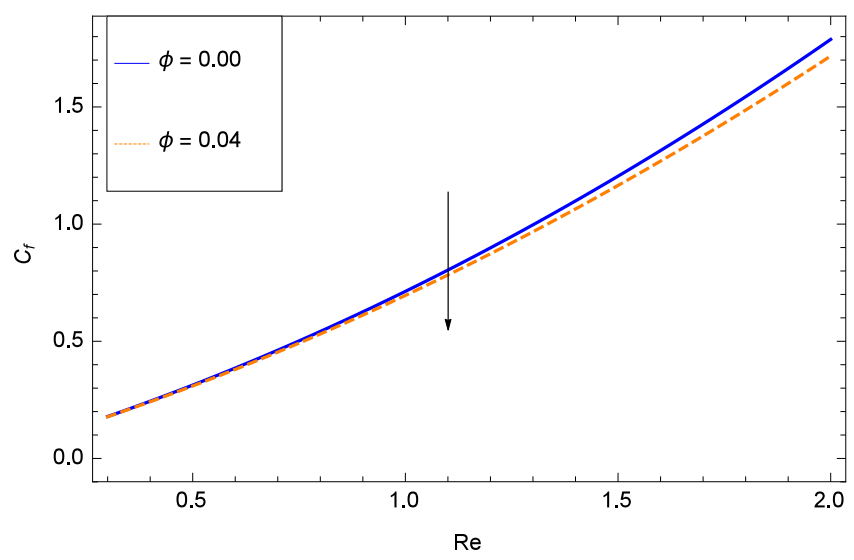

Figure 22. Skin friction coefficient $\left(C_{f}\right)$ when $h=-0.40, \beta_{1}=2.00, M=0.10, \operatorname{Pr}=6.80$ and various values of $\phi$ against Reynolds number $R e$ for $\left(\mathrm{CuO}-\mathrm{H}_{2} \mathrm{O}\right)$.

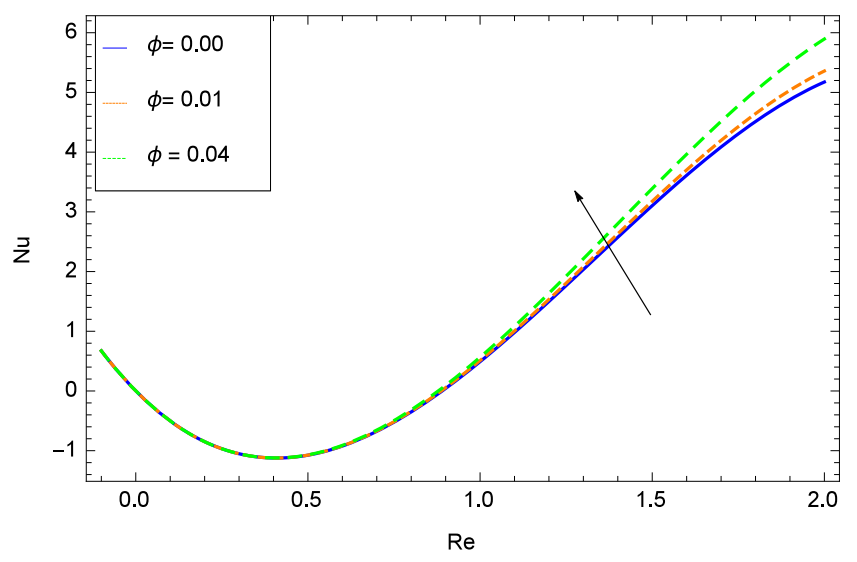

Figure 23. Nusselt number $(\mathrm{Nu})$ when $h=-0.40, \beta_{1}=0.10, M=0.10, \operatorname{Pr}=6.80$ and various values of $\phi$ against Reynolds number $\mathrm{Re}$ for $\left(\mathrm{CuO}-\mathrm{H}_{2} \mathrm{O}\right)$. 
Table 5. Comparison of the effects of different kinds of nanoparticles on skin friction coefficient $\left(C_{f}\right)$ as a function of Reynolds number $\operatorname{Re}$ when $\phi=0.04$.

\begin{tabular}{cccc}
\hline Parameter & Sheikhoeslami [45] & Sheikhoeslami [45] & $\begin{array}{c}\text { Present Study (When } \boldsymbol{h}=\mathbf{- 0 . 2 0} \\
\left.\boldsymbol{\beta}_{\mathbf{1}}=\mathbf{0 . 5 0 ,} \boldsymbol{M = 0 . 1 0 ,} \boldsymbol{P r}=\mathbf{6 . 8 0}\right)\end{array}$ \\
\hline $\operatorname{Re}$ & $\mathrm{CuO}$ & $\mathrm{Al}_{2} \mathrm{O}_{3}$ & $\mathrm{CuO}$ \\
0.1 & 0.679741 & 0.703897 & 0.577056 \\
1 & 1.194617 & 1.224377 & 0.215528 \\
2 & 1.579317 & 1.615502 & 0.384453 \\
\hline
\end{tabular}

Table 6. Comparison of the effects of different kinds of nanoparticles on Nusselt number $(\mathrm{Nu})$ as a function of Reynolds number $\operatorname{Re}$ when $\phi=0.04$.

\begin{tabular}{cccc}
\hline Parameter & Sheikhoeslami [45] & Sheikhoeslami [45] & $\begin{array}{c}\text { Present Study (When } \boldsymbol{h}=\mathbf{- 0 . 4 0} \\
\left.\boldsymbol{\beta}_{\mathbf{1}}=\mathbf{0 . 1 0}, \boldsymbol{M}=\mathbf{0 . 1 0}, \boldsymbol{P r}=\mathbf{6 . 8 0}\right)\end{array}$ \\
\hline$R e$ & $\mathrm{CuO}$ & $\mathrm{Al}_{2} \mathrm{O}_{3}$ & $\mathrm{CuO}$ \\
0.1 & 1.846686 & 1.70097 & 0.227864 \\
1 & 4.324278 & 4.113995 & 2.25099 \\
2 & 5.996721 & 5.711652 & 4.40516 \\
\hline
\end{tabular}

\section{Conclusions}

This article explores the analytical solution of magnetohydrodynamic thin film $\mathrm{CuO}-\mathrm{H}_{2} \mathrm{O}$ nanofluid sprayed on a stretching cylinder accompanying transfer of heat. The solution of the problem has been achieved by using analytical technique HAM (Homotopy Analysis Method) for the velocity profile and temperature distribution. Pressure distribution and rate of spray are also investigated. From the given figures, it is clear that the types of nanofluids and various parameters have an effective contribution in the flow, transfer of heat, pressure distribution and rate of spray. The solution has been displayed in the diagrams and the influences of all the parameters included in the problem on the $\mathrm{CuO}-\mathrm{H}_{2} \mathrm{O}$ nanofluid have been described graphically for checking their effects on velocity profile, temperature distribution and pressure distribution accompanying spray distribution. It is predicted that the model of the problem can be used in technical procedures, cooling/heating techniques and in the modeling of coating processes by employing the constitutive equations of the problem. The findings of the research are the following:

(i) The velocity depreciates for the thin film nanofluid parameter $\beta_{1}$, Reynolds number $R e$ and magnetic field parameter $M$.

(ii) Temperature diminishes for the thin film parameter $\beta_{1}$, Prandtl number $\mathrm{Pr}$ and it enhances for the Reynolds number $R e$ and it elevates for the magnetic field parameter $M$.

(iii) Volume fraction parameter $\phi$ has no sensitive effect on velocity and temperature.

(iv) Pressure depreciates for the Reynolds number Re and magnetic field parameter $M$ while it elevates for the thin film parameter $\beta_{1}$, volume fraction parameter $\phi$.

(v) Film size $\beta_{1}$ enhances with the spray rate, but nonlinearly.

(vi) Comparisons of HAM solution with the numerical method solution for velocity and temperature are performed and the results are found to be in good agreement.

(vii) The residual errors show the authentication of the present work.

(viii) Skin friction coefficient $\left(C_{f}\right)$ as a function of Reynolds number Re decreases with the increase of nanoparticle volume fraction $\phi$.

(ix) Nusselt number $N u$ as a function of Reynolds number Re increases with the increase of nanoparticle volume fraction $\phi$.

(x) The present study shows an excellent agreement with the published experimental work. 
Acknowledgments: The authors greatly acknowledge with thanks the Deanship of Scientific Research (DSR) at King Abdulaziz University, Jeddah, Saudi Arabia for technical and financial support. The authors are cordially thankful to the honorable reviewers for their constructive comments to improve the quality of the paper.

Author Contributions: Noor Saeed Khan and Taza Gul modeled and solved the problem. Noor Saeed Khan wrote the paper also. Saeed Islam and Ilyas Khan made the corrections. Aisha M. Alqahtani and Ali Saleh Alshomrani arranged the paper.

Conflicts of Interest: The authors declare no conflict of interest.

\section{Abbreviations}

The following abbreviations are used in this manuscript:

MDPI Multidisciplinary Digital Publishing Institute

DOAJ Directory of open access journals

TLA Three letter acronym

LD linear dichroism

\section{References}

1. Choi, S.U.S. Enhancing thermal conductivity of fluids with nanoparticles. In Developments and Applications of Non-Newtonian Ows; Siginer, D.A., Wang, H.P., Eds.; ASME: New York, NY, USA, 1995; Volume 66, pp. 99-105.

2. Yu, W.; Xie, H.Q.; Chen, L.F.; Li, Y. Investigation on the thermal transport properties of ethylene glycol-based nanofluids containing copper nanoparticles. Powder Technol. 2010, 197, 218-221.

3. Yu, W.; Xie, H.Q.; Li, Y.; Chen, L.F. Experimental investigation om the heat transfer properties of $\mathrm{Al}_{2} \mathrm{O}_{3}$ nanofluids using the mixture of ethylene. Powder Technol. 2012, 230, 14-19.

4. Chen, L.F.; Yu, W.; Xie, H.Q.; Li, Y. Enhanced thermal conductivity of nanofluids containing Ag/MWNT composites. Powder Technol. 2012, 231, 18-20.

5. Xie, H.Q.; Chen, L.F.J. Review on the preparation and thermal performances of carbon nanotube contained nanofluids. Chem. Eng. Data 2011, 56, 1030-1041.

6. Yu, W.; Xie, H.Q.; Chen, W. Experimental investigation on thermal conductivity of nanofluids containing graphene oxide nanosheets. J. Appl. Phys. 2010, 107, 094317.

7. Xiao, B.; Yang, Y.; Chen, L. Developing a novel form of thermal conductivity of nanofluids with Brownian motion effect by means of fractal geometry. Powder Technol. 2013, doi:10.1016/j.powtec.2013.02.029

8. Cai, J.; Hu, X.; Xiao, B.; Zhou, Y.; Wei, W. Recent developments on fractal-based approaches to nanofluids and nanoparticles aggregation. Int. J. Heat Mass Transf. 2017, 105, 623-637.

9. Buongiorno, J. Convective transport in nanofluids. ASME J. Heat Transf. 2006, 128, 240-250.

10. Ellahi, R. The effects of MHD and temperature dependent viscosity on the flow of a non-Newtonian nanofluid in a pipe: Analytical solution. Appl. Math. Model. 2013, 37, 1451-1457.

11. Khan, W.A.; Pop, I. Boundary layer flow of a nanofluid past a stretching sheet. Int. J. Heat Mass Transf. 2010, 53, 2477-2483.

12. Mustafa, M.; Hina, S.; Hayat, T.; Alsaedi, A. Influence of wall properties on the peristaltic flow of a nanofluid: Analytic and numerical solutions. Int. J. Heat Mass Transf. 2012, 55, 4871-4877.

13. Akbar, N.S.; Nadeem, S. Endoscopic effects on peristaltic flow of a nanofluid. Commun. Theor. Phys. 2011, 56, 761-768.

14. Nowar, K. Peristaltic flow of a nanofluid under the effect of Hall current and porous medium. Hindawi Publ. Corp. Math. Probl. Eng. 2014, 2014, doi:10.1155/2014/389581.

15. Choi, S.U.S.; Zhang, Z.G.; Yu, W.; Lockwood, F.E.; Grulke, W.A. Anomalously thermal conductivity enhancement in nanotube suspensions. Appl. Phys. Lett. 2001, 79, 2252-2254.

16. Terekhov, V.I.; Kalinina, S.V.; Lemanov, V.V. The mechanism of heat transfer in nanofluids, State of the Art (Review): Part 1. Synthesis and properties of Nanofluids. Thermophys. Aeromech. 2010, 17, 1-4.

17. Yu, W.; France, D.M.; Routbort, J.L.; Choi, S.U.S. Review and comparison of nanofluids thermal conductivity and heat transfer enhancements. Heat Transf. Eng. 2008, 29, 432-460.

18. Hojjat, M.; Etmat, S.G.; Bagheri, R.; Thibault, J. Laminar convective heat transfer of Non-Newtonian nanofluids with constant wall temperature. Heat Mass Transf. 2011, 47, 203-209. 
19. He, Y.; Men, Y.; Liu, X.; Lu, H.; Chen, H.; Ding, Y. Study on forced convective heat transfer of Non-Newtonian nanofluids. J. Therm. Sci. 2009, 18, 20-26.

20. Polidoiri, G.; Fohanno, S.; Nguyen, C.T. A note on heat transfer modeling of Newtonian nanofluids in laminar free convection. Int. J. Therm. Sci. 2007, 46, 739-744.

21. Lakshmisha, K.N.; Venkatswaran, S.; Nath, G. Three-Dimensional unsteady flow with heat and mass transfer over a continuous stretching surface. J. Heat Transf. 1988, 110, 590-595.

22. Wang, C.Y. The three-dimensional unsteady flow due to a stretching flat surface. Phys. Fluids 1984, 27, 1915-1917.

23. Ahmad, S.; Rohni, A.M.; Pop, I. Blasius and Sakiadis problems in nanofluids. Acta Mech. 2011, 218, $195-204$.

24. Chamkha, A.J.; Aly, A.M.; Al Mudhaf, H. Laminar MHD mixed convection flow of a nanofluid along a stretching permeable surface in the presence of heat generation or absorption effects. Int. J. Microscale Nanoscale Therm. Fluid Transp. Phenom. 2011, 2, 51-70.

25. Kandasamy, R.; Loganathan, P.; Puvi Arasu, P. Scaling group transformation for MHD boundary layer flow of a nanofluid past a vertical stretching surface in the presence of suction and injection. Nuclear Eng. Des. 2011, 241, 2053-2059.

26. Sakiadis, B.C. Boundary layer behavior on continuous solid surface: Boundary layer on a continuous flat surface. Am. Inst. Chm. Eng. J. 1961, 7, 213-215.

27. Crane, L.J. Flow past a stretching sheet. Zeits für Ange Math. Phys. 1970, 21, 645-647.

28. Vajravelu, K.; Rollins, D. Hydromagnetic flow of a second grade fluid over a stretching sheet. Appl. Maths. Comput. 2004, 148. 783-791.

29. Abu-Nada, E. Effects of variable viscosity and thermal conductivity of $\mathrm{Al}_{2} \mathrm{O}_{3}$ water nanofluid on heat transfer enhancement in natural convection. Int. J. Heat Fluid Flow 2009, 30, 679-690.

30. Nasrin, R.; Alim, M.A. Entropy generation by nanofluid with variable thermal conductivity and viscosity in a flat plate solar collector. Int. J. Eng. Sci. Technol. 2015, 7, 80-93.

31. Khan, Y.; Wua, Q.; Faraz, N.; Yildirim, A. The effects of variable viscosity and thermal conductivity on a thin film flow over a shrinking/stretching sheet. Comput. Math. Appl. 2011, 61, 3391-3399.

32. Khan, N.S.; Gul, T.; Islam, S.; Khan, W.; Khan, I.; Ali, L. Thin film flow of a second-grade fluid in a porous medium past a stretching sheet with heat transfer. Alex. Eng. J. 2017, in press.

33. Khan, N.S.; Gul, T.; Islam, S.; Khan, W. Thermophoresis and thermal radiation with heat and mass transfer in a magnetohydrodynamic thin film second-grade fluid of variable properties past a stretching sheet. Eur. Phys. J. Plus 2017, 132, doi:10.1140/epjp/i2017-11277-3.

34. Aziz, R.C.; Hashim, I.; Alomari, A.k. Thin film flow and heat transfer on an unsteady stretching sheet with internal heating. Meccanica 2011, 46, 349-357.

35. Khan, W.; Gul, T.; Idrees, M.; Islam, S.; Dennis, L.C.C. Thin film Williamson nanofluid flow with varying viscosity and thermal conductivity on a time-dependent stretching sheet. Appl. Sci. 2016, 6, 334.

36. Qasim, M.; Khan, Z.H.; Lopez, R.J.; Khan, W.A. Heat and mass transfer in nanofluid over an unsteady stretching sheet using Buongiorno's model. Eur. Phys. J. Plus 2016, 131, 1-16.

37. Prashant, G.M.; Jagdish, T.; Abel, M.S. Thin film flow and heat transfer on an unsteady stretching sheet with thermal radiation, internal heating in presence of external magnetic field. arXiv:1603.3664 physics. flu-dyn. 2016, 3, 1-16.

38. Kumari, M.; Gireesha, B.J.; Gorla, R.S.R. Heat and mass transfer in nanofluid over an unsteady stretching surface. J. Nanofluids 2015, 4, 1-8.

39. Wang, C.Y. Fluid flow due to a stretching cylinder. Phys. Fluids 1988, 31, 466-468.

40. Ishak, A.; Nazar, R.; Pop, I. Magnetohydrodynamic (MHD) flow and heat transfer due to a stretching cylinder. Energ. Convers. Manag. 2008, 49, 3265-3269.

41. Wang, C.Y. Natural convection on a cylinder. Commun. Nonlinear Sci. Numer. Simul. 2012, 17, 1098-1103.

42. Elbashbeshy, E.M.A.; Emam, T.G.; El-Azab, M.S.; Abdelgaber, K.M. Effect of magnetic field on flow and heat transfer over a stretching cylinder in the presence of a heat source/sink with suction/injection. J. App. Mech. Eng. I 2012, 106, doi:10.4172/2168-9873.1000106.

43. Ashorynejad, H.R.; Sheikoleslami, M.; Pop, I.; Ganji, D.D. Nanofluid flow and heat transfer due to a stretching cylinder in the presence of magnetic field. Heat Mass Transf. 2012, 49, 427-436.

44. Rangi, R.R.; Ahmad, N. Boundary layer flow past a stretching cylinder and heat transfer with variable thermal conductivity. Appl. Math. 2012, 3, 205-209. 
45. Sheikholeslami, M. Effect of uniform suction of nanofluid flow and heat transfer over a cylinder. Braz. Soc. Mech. Sci. Eng. 2014, doi:10.1007/40430-014-0242-z.

46. Wang, C.Y. Liquid film sprayed on on a stretching cylinder. Chem. Eng. Commun. 2006, 193, 869-878.

47. Koo, J.; Kleinstreuer, C. Viscous dissipation effects in micro tubes and micro channels. Int. J. Heat Mass Transf. 2004, 47, 3159-3169.

48. Koo, J. Computational Nanofluid Flow and Heat Transfer Analysis Applied to Microsystems. Ph.D. Thesis, NC State University, Raleigh, NC, USA, 2004.

49. Prasher, R.S.; Bhattacharya, P.; Phelan, P.E. Thermal conductivity of nano scale colloidal solution. Phys. Rev. Lett. 2005, 94, 025901.

50. Jang, S.P.; Choi, S.U.S. The role of Brownian motion in the enhanced thermal conductivity of nanofluids. Appl. Phys. Lett. 2004, 84, 4316-4318.

51. Li, J. Computational Analysis of Nanofluid Flow in Micro Channels with Applications to Micro-Heat Sinks and Bio-MEMS. Ph.D. Thesis, NC State University, Raleigh, NC, USA, 2008.

52. Koo, J.; Kleinstreuer, C. Laminar nanofluid flow in micro-heat-sinks. Int. J. Heat Mass Transf. 2005, 48, 2652-2661.

53. Brinkman, H.C. The viscosity of concentrated suspensions and solutions. J. Chem. Phys. 1952, $20,571$.

54. Einstein, A. Investigation on the Theory of Brownian Motion; Dover Publications, Inc.: New York, NY, USA, 1956.

55. Liao, S.J. Homotopy Analysis Method in Non-Linear Differential Equations; Higher Education Press: Beijing, China; Springer: Berlin/Heidelberg, Germany, 2012.

56. Liao, S.J. On the homotopy analysis method for non-linear problems. Appl. Math. Comput. 2004, 147, 499-513.

57. Liao, S.J. Homotopy analysis method: A new analytic method for non-linear problems. Appl. Math. Mech. 1998, 19, 957-962.

58. Gupta, V.G.; Gupta, S. Application of homotopy analysis method for solving nonlinear Cauchy problem. Surv. Math. Appl. 2012, 7, 105-116.

(C) 2017 by the authors. Licensee MDPI, Basel, Switzerland. This article is an open access article distributed under the terms and conditions of the Creative Commons Attribution (CC BY) license (http:/ / creativecommons.org/licenses/by/4.0/). 